\title{
Fibroblast Growth Factor Signalling in the Diseased Nervous System
}

\author{
Lars Klimaschewski $^{1}$ (D) Peter Claus $^{2,3}$ \\ Received: 2 February 2021 / Accepted: 19 March 2021 / Published online: 15 April 2021 \\ (C) The Author(s) 2021
}

\begin{abstract}
Fibroblast growth factors (FGFs) act as key signalling molecules in brain development, maintenance, and repair. They influence the intricate relationship between myelinating cells and axons as well as the association of astrocytic and microglial processes with neuronal perikarya and synapses. Advances in molecular genetics and imaging techniques have allowed novel insights into FGF signalling in recent years. Conditional mouse mutants have revealed the functional significance of neuronal and glial FGF receptors, not only in tissue protection, axon regeneration, and glial proliferation but also in instant behavioural changes. This review provides a summary of recent findings regarding the role of FGFs and their receptors in the nervous system and in the pathogenesis of major neurological and psychiatric disorders.
\end{abstract}

Keywords FGF · FGFR · Receptor · CNS · Brain · Spinal cord · PNS · Nerve · Ganglia · Regeneration · Degeneration · Remyelination $\cdot$ Demyelination $\cdot$ Glioma $\cdot$ Anxiety $\cdot$ Depression $\cdot$ Schizophrenia

\section{Introduction}

\section{The FGF and FGF Receptor Families}

Fibroblast growth factors (FGFs) comprise a large family of polypeptides. They are expressed in nearly all organisms, ranging from nematodes to vertebrates. The 22 members of the FGF family are highly conserved in gene structure and amino acid sequence. Several of these factors are secreted and implicated in differentiation and migration during organ development. Ten of them are expressed in the brain [1]. FGF3, FGF8, FGF15, FGF17, and FGF18 play key roles in early development by imparting positional information and regulation of gene expression involved in brain patterning [2]. At the adult stage, FGFs primarily act as homeostatic factors in tissue repair and cellular proliferation. Several FGFs and their receptors (listed in Table 1) have been demonstrated to be involved in the pathogenesis of neurological disorders including Parkinson's and Alzheimer's [3, 4] and

Lars Klimaschewski

lars.klimaschewski@i-med.ac.at

1 Department of Anatomy, Histology and Embryology, Institute of Neuroanatomy, Medical University of Innsbruck, Innsbruck, Austria

2 Institute of Neuroanatomy and Cell Biology, Hannover Medical School, Hannover, Germany

3 Center for Systems Neuroscience, Hannover, Germany will be the focus of this review. The experimental data presented here were mainly obtained in rats and mice, the leading model organisms used in biomedical research. Very few aspects were validated in humans, and those are included as well.

FGF1 and FGF2 (acidic and basic FGF) are the most widely studied members of the FGF family expressed in neurons and glial cells [5]. An unusual feature of those ligands is the lack of a conventional signal sequence for export out of the cell and their exit via non-canonical mechanisms. Other FGFs like FGF11-14 remain intracellular and exert intracrine functions [6]. Some translocate from early endosomes into the cytosol and enter the nucleus [7]. This complexity is further enhanced by the expression of isoforms. For example, human FGF2 is expressed in five different isoforms derived from a single mRNA species [8]. This is the result of N-terminal sequence extensions in higher molecular weight isoforms as compared with low molecular weight FGF2 in some species $[9,10]$. While the intranuclear functions of FGF1 and FGF2 are not fully understood [11], signalling through membranebound tyrosine kinase receptors has been described in detail [12]. Different FGF subfamilies exhibit preferences for one of the FGF receptors (FGFRs). FGF1 is the only member that can activate all four FGFR variants.

FGFRs share $46 \%$ amino acid identity and code for receptors of 125-160 kDa molecular weight. A fifth FGFR, FGFRL1, lacks the tyrosine kinase domain and is a putative co-receptor for FGFR1 [13]. FGFR1-3 are characterised by three extracellular immunoglobulin (Ig)-like domains, a 
Table 1 Summary of confirmed expression and functional significance of the most relevant FGFs and FGFRs in the nervous system (+ indicates presence or positive effect, - indicates absence or negative effect; see text for references)

\begin{tabular}{|c|c|c|c|c|c|c|c|c|c|c|}
\hline FGF & -1 & -2 & -7 & -8 & -9 & -20 & -22 & $\mathrm{R} 1$ & $\mathrm{R} 2$ & R3 \\
\hline Absolutely required for CNS development & & & & + & & & & + & + & \\
\hline Abundance in the adult nervous system & + & + & & & & & & + & + & + \\
\hline Lack of signal peptide & + & + & & & + & + & & & & \\
\hline Nuclear localisation & + & + & & & & & & + & & \\
\hline Expressed in neurons & + & + & + & + & + & + & + & + & + & + \\
\hline Expressed in astrocytes & + & + & & & + & & & + & + & + \\
\hline Expressed in oligodendrocytes & + & + & & & + & & & + & + & + \\
\hline Expressed in microglia & + & + & & & & & & + & & + \\
\hline Schwann cell proliferation & & + & & & & & & + & + & \\
\hline Astrocyte proliferation & + & + & & & & & & + & + & \\
\hline Glioma proliferation & + & + & & & & & & + & $(-)$ & + \\
\hline Enhanced ECM production & & + & & & & & & & & \\
\hline Neurogenesis & & + & & + & & + & & + & + & \\
\hline Excitatory synapse formation & & & & & & & + & + & + & \\
\hline Inhibitory synapse formation & & & + & & & & & & + & \\
\hline Stimulation of LTP & + & + & & & & & & + & & \\
\hline Neuronal survival & + & + & + & + & & + & & + & & - \\
\hline Up-regulation after peripheral nerve lesion & + & + & + & & & & & & & + \\
\hline Promotion of axonal regeneration in the PNS & + & + & & & & & & + & & \\
\hline Axonal elongation (in pre-lesioned neurons) & + & + & & & & & & + & & \\
\hline Axonal branching (in naive neurons) & + & + & & & & & & + & & \\
\hline Interaction with myelin inhibitory signalling & + & + & & & & & & + & & \\
\hline Noci- and thermoception & & + & + & & & & & + & + & \\
\hline Seizure induction & - & + & - & & & & + & & & \\
\hline
\end{tabular}

heparin-binding region, and an acidic box domain. Ligand binding to D2 and D3 domains results in a 2:2:2 ternary complex of FGF, FGFR, and heparan sulphate [14]. The Ig-like D1 domain and the acidic box, located between D1 and D2, inhibit ligand binding by electrostatic interactions [15]. Alternative splicing in the D3 domain generates the IIIb and IIIc isoforms of FGFR1-3 with different ligand-binding properties (FGFR1b, -1c, $-2 b,-2 c,-3 b$, and $-3 c$ ). The $b$ and $c$ isoforms are restricted mainly to epithelial and mesenchymal tissues, respectively [16]. The extracellular D2 domain interacts with heparan sulphate proteoglycans (HSPGs) that facilitate the dimerisation and stabilisation of ligand interactions. The intracellular region of FGFRs beneath the transmembrane segment harbours a split tyrosine kinase domain. The binding of FGFs at HSPGs allows the formation of defined ligand gradients required for paracrine signalling, in particular during development.

\section{Nuclear FGFR Signalling}

In addition to its canonical role as membrane-bound tyrosine kinase receptor, FGFR1 has been described as a nuclear protein [17]. It translocates to the nucleus via an importin- $\beta$ - dependent mechanism [18]. On the functional level, the nuclear receptor is a major signalling hub (designated as nuclear FGFR1 signalling, INFS) regulating neuronal growth and differentiation, amongst others [11, 19, 20]. Nuclear FGFR1 colocalises with transcriptionally active chromatin, binds to CREB-binding protein (CBP) or ribosomal S6 kinase isoform 1 (RSK1), and forms complexes with retinoid and Nurr receptors. Developmental signals are thereby directly forwarded to CBP and RSK1. RSK1 binding promotes FGFR1 release from the pre-Golgi to the cytosol, increases the mobile population of FGFR1, and facilitates nuclear accumulation. Novel interactive features of FGFR1 allow the newly synthesised $90 \mathrm{kDa}$ protein to be released from pre-Golgi membranes and translocate into the cell nucleus along with the nuclear localisation signal (NLS)-containing FGF2 ligand [21]. Granzyme B-dependent cleavage of the C-terminal part of FGFR1 may also play a role [22]. The mRNAs for FGF2 and tyrosine hydroxylase are up-regulated in response to the nuclear shuttling of the receptor [23]. Importantly, nerve growth factor (NGF) utilises INFS for its neurodevelopmental and gene-activating functions [24]. NGF induces process outgrowth and transcriptional programming in a neuronal cell line (PC12) via nuclear translocation of FGFR1. FGFR1 
interacts with the orphan nuclear receptor Nurr1, and this complex regulates tyrosine hydroxylase $(\mathrm{TH})$ expression by binding to the TH gene promoter [25]. Furthermore, INFS appears to be necessary for dendritic outgrowth of sympathetic neurons in response to bone morphogenetic protein, BMP7 [26]. Recent evidence suggests a broader function of nuclear FGFR1 on several genes relevant in nuclear development [21, 27].

\section{Distribution of FGF Receptors in the Nervous System}

FGFR1-3 are widely distributed in the brain and bind to FGF ligands with different affinities and specificities [28, 29]. FGFR 4 plays a role in early brain development but is absent from the adult brain (apart from one small nucleus). FGFR1 is most abundant in the nervous system with a predominant expression in neurons, astrocytes, and radial glia [30]. FGFR2 and FGFR3 are preferentially expressed in astrocytes and oligodendrocytes [1]. Studies of mice carrying null mutations in each of the FGFR genes revealed that FGFR1 and FGFR2 are essential for early embryonic development, which reflects their key roles in neuralisation and precursor proliferation. In contrast, animals lacking FGFR3 survive and exhibit no obvious telencephalic defects. However, FGFR3 plays an important role in cortex development [3]. Mutations in FGFR2 lead to either Apert or Crouzon syndrome, resulting in prominent changes of several brain structures [31].

The overlapping pattern of FGF ligand binding to similar FGF receptors implies a certain level of redundancy. In fact, different FGF family members activate FGFR subtypes to different degrees, depending on their ability to bind with high or low affinity to each receptor subtype [32]. Moreover, receptor specificity is modulated by the expression of other receptors and by the specific lipid composition of the plasma membrane. For example, in oligodendrocytes, a fraction of FGFR2 resides within the cholesterol/glycosphingolipidenriched membrane microdomains (lipid rafts) [33]. Lipid rafts concentrate and segregate surface receptors together with their signalling molecules, and this compartmentalises and enhances intracellular signal transduction [34].

The complexity of FGFR activation is further increased by membrane molecules that may directly bind to and activate FGFRs in the absence of canonical ligands. Some of them play a pivotal role in the nervous system. For example, neural cell adhesion molecule (N-CAM), neuronal cadherin (Ncadherin), Eph receptor A4 (EphA4), and Anosmin-1 use FGFR as a signalling mediator and interfere with intracellular FGFR transport [35-37]. Hence, FGFRs are not specific to FGFs, and the phenotype of mice deficient in one or more FGFRs may be due to the lack of FGFR activation by ligands unrelated to FGFs or other receptors.

\section{Signal Transduction of FGF Receptors}

Ligand binding in cooperation with accessory HSPG triggers dimerisation of receptor monomers. This results in their mutual activation [38]. All possible FGFR combinations formed amongst FGFR1-3 suggest that FGFR heterodimers are as functionally important as homodimers [39]. FGFR dimers may also form in the absence of ligands at their physiological concentrations (Fig. 1). The ligand-independent dimers are stabilised through contacts below the transmembrane domains. These receptors are auto-phosphorylated, which explains why FGFR overexpression can lead to certain forms of cancer. The primary effect of ligand binding lies in a structural change in the pre-formed dimers and thereby enhanced receptor phosphorylation. Diverse ligands change receptor kinase activities in different ways. For example, FGF2-bound dimers show the smallest separation between the transmembrane domains but the highest possible phosphorylation [40].

Phosphorylated FGFRs activate canonical scr-homology 2 (SH2)-linked signalling proteins (PLC $\gamma, \mathrm{CRKL}$ ) and recruit adapter proteins for connecting the receptor to PI3K/MAPK pathways. The analysis of chimeric receptors composed of cytoplasmic FGFRs and extracellular PDGF receptors has revealed that all FGFR subtypes stimulate the same pathways but with different magnitudes [38]. Prominent differences are found between FGFR1/FGFR2 and FGFR3/FGFR4 signalling. This may be due to differences in ligand activation and/ or intracellular receptor transport following internalisation. For example, FGFR1 activates ERK and PLC $\gamma$ more strongly than FGFR4, and higher ERK activation is caused by FGFR1 rather than by FGFR2 [16].

Key signalling hubs such as PI3K and Ras/ERK are recruited by the lipid-anchored $80 \mathrm{kDa}$ docking protein FRS2 (also referred to as SNT1). FRS2 constitutively binds the juxtamembrane region of FGFR1 and is phosphorylated most efficiently by FGFR1 as compared with other receptor isoforms [41]. Activated FRS2 $\alpha$ associates with the Grb2/SOS complex to relay activation of Ras and downstream MAPK signalling [42]. Additionally, FRS $2 \alpha$ recruits the tyrosine phosphatase SHP2 [43]. FRS2 $\alpha$ is also involved in neurotrophin receptor (Trk) signalling and appears to act as a 'conning centre' responsible for differential pathway activation. Furthermore, FRS2 is crucial for FGFR ubiquitination and trafficking due to its ability to constitute local signalling platforms and to recruit feedback inhibitors [44]. The latter initiate a cascade of negative signalling events that decrease the amplitude of positive signals and modulate the level of stimulation.

Six tyrosine $(\mathrm{Y})$ residues in the split kinase domain need to be sequentially phosphorylated for the full activation of at least four major signalling pathways (Y653 $\rightarrow$ Y583 $\rightarrow$ Y463, Y766, and Y585 $\rightarrow$ Y654) [12]. Y653 increases tyrosine kinase activity by fifty- to one hundred-fold, and Y 654 by 


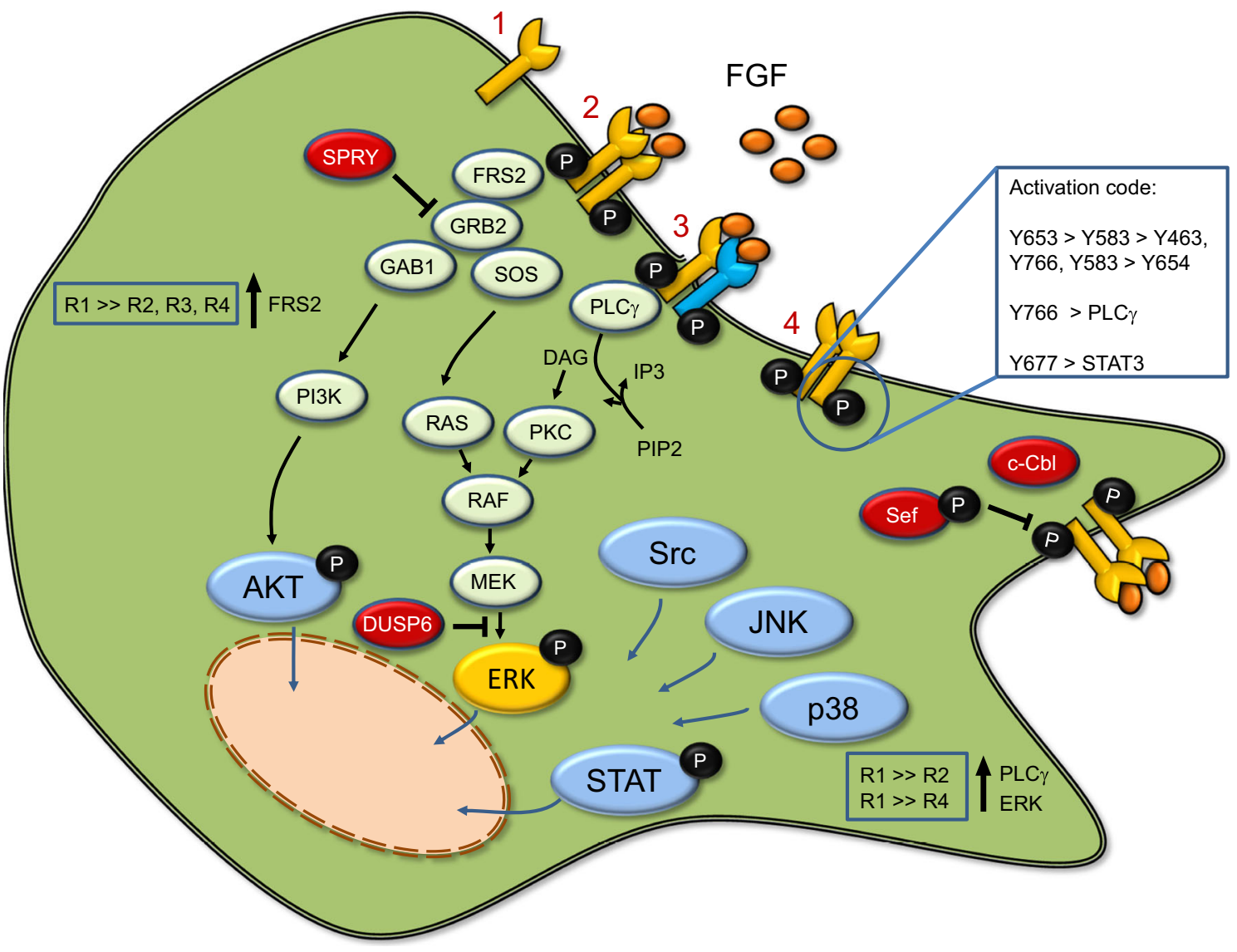

Fig. 1 The neuronal FGFR signalling network, from the binding of ligands to downstream events. FGFR1-3 monomers (1) form homodimers (2) and heterodimers (3) either in a ligand-dependent $(2,3)$ or independent (4) mode. The latter may undergo autophosphorylation. FGF ligand binding leads to enhanced receptor phosphorylation. The ordered and cooperative post-translational modifications are depicted as an activation code with sequentially phosphorylated tyrosine residues (boxed inset, 4). Certain downstream pathways like PLC $\gamma$ and STAT3 require specific phosphorylation of additional tyrosine residues. Phosphorylation activates downstream pathways such as PLC $\gamma$, AKT,

a further ten-fold. Additional tyrosines are required for the activation of phospholipase $\mathrm{C} \gamma$ (Y766) and STAT3 (Y677). The STAT pathway changes nuclear gene expression, whereas activation of PLC $\gamma$ at the plasma membrane produces inositol trisphosphate (IP3) and diacylglycerol (DAG), thereby releasing calcium from endoplasmic reticulum stores and causing the activation of protein kinase $\mathrm{C}$ ( $\mathrm{PKC}$ ), respectively. DAG also produces ligands that can activate the endocannabinoid receptor CB1 in the brain [45]. Importantly, cannabinoid receptors transactivate FGFR1 in lipid rafts [46].

Inhibitory feedback mechanisms are induced by FGFR stimulation, which is essential to limit excessive signalling. Their de-regulation may result in brain tumours. They involve the coordinated action of ubiquitin ligase (c-Cbl), adapters (Grb2) and proteins such as Sef, phosphatases (DUSP), and Sprouty proteins $[47,48]$. The latter function as crucial FGFR antagonists during brain development and in the adult, mainly
ERK, and STAT3. These are regulated by a number of proteins that provide an inhibitory feedback, thereby limiting activation (SPRY, Sef, and DUSP6; depicted in red). The lipid-anchored fibroblast growth factor receptor substrate 2 (FRS2) undergoes phosphorylation by FGFR kinase activity and recruits downstream factors PI3K and Ras/ERK as signalling hubs. However, this mechanism is FGFR-specific, with FGFR1 showing higher activity than the other FGFRs (boxed inset). Moreover, FGFR subtypes differentially activate downstream ERK and PLC $\gamma$ with FGFR1 showing stronger activation than FGFR2 or FGFR4, respectively (boxed inset). For references, see text

by interfering with processes upstream of ERK [49]. Interestingly, FGFRs themselves are the subject of negative feedback mechanisms, because the prevention of ERKdependent phosphorylation at serine 777 of FGFR1 (or the mutation of this serine to alanine) promotes receptor tyrosine phosphorylation and, consequently, cellular proliferation, migration, and axon growth [50].

\section{Intracellular FGF Receptor Transport}

FGFR activation is followed by rapid endocytosis and degradation of the receptor and the ligand. Ligand binding induces receptor mono-ubiquitination by the ubiquitin ligase $\mathrm{c}-\mathrm{Cbl}$, which functions as a signal for the sorting of the receptor into intraluminal vesicles of multivesicular endosomes and its subsequent delivery to lysosomes [51]. Receptor tyrosine kinases, such as FGFR, EGFR, and PDGFR, are mono-ubiquitinylated 
at multiple sites, while cytoplasmatic phosphorylated protein tyrosine kinases are poly-ubiquitinylated and degraded in the proteasome [52]. In the case of FGFR signalling, c-Cbl does not directly bind to the receptor but catalyses the ubiquitination of the receptor via interaction with FRS2 and Grb2. Hence, the competition of c-Cbl with SOS for Grb2 abrogates MAPK signalling [53].

The transport of FGFRs from the cell surface to different subcellular compartments influences the biological response to receptor activation. This has recently been confirmed by optogenetics [54]. Overexpressed FGFR1-eGFP fusion proteins bind FGF2 and activate signalling hubs at various locations. FGFRs internalise and shuttle to the recycling and degradation compartments in neurons and glial cells. This has consequences for the strength and duration of signalling pathway activation $[55,56]$.

Plasma membrane levels of neuronal FGFRs at the adult stage appear to be significantly lower than those of neurotrophin receptors, because the effects of neurotrophins on neuronal survival and neurite outgrowth are significantly stronger when compared with FGFs. However, overexpression of FGFR1 stimulates axon growth [57]. This effect is further enhanced by protease inhibitors such as leupeptin, which inhibits lysosomal protein degradation and promotes receptor recycling [58].

RTK recycling depends on the number of intracellular lysine residues that are required for receptor ubiquitination. For example, FGFR1 comprises 29 lysine residues, while the intracellular part of FGFR4 harbours 16 lysine residues only. Accordingly, lysine mutants of FGFR1 that are deficient in ubiquitination will be sorted to the recycling pathway rather than to degradation in lysosomes [59]. Overexpression of FGFR1 mutants exhibiting reduced numbers of lysines modifies axon outgrowth [60]. FGFR1-15R (with 14 instead of 29 lysine residues) preferentially recycles back to the plasma membrane similarly to FGFR4 and strongly promotes elongative axon growth without stimulating axon branching. Interestingly, the ERK inhibitor PD98059 does not reduce elongative axon growth induced by FGFR1-15R overexpression. This raises the possibility that ERK has independent effects on the axonal cytoskeleton through enhanced receptor recycling of FGFR1 which probably shows increased interaction with other growth promoting membrane receptors (e.g., NCAM [61]). The functional significance of the Ras/RAF/ERK pathway for adult axon regeneration remains a subject of controversy because in some studies ERK inhibitors did not interfere with axon outgrowth of adult primary neurons in culture [62].

\section{FGFs in Neurological Disorders}

\section{Neuronal Degeneration and Repair}

As master regulators of brain organogenesis and homeostasis, FGFs play an important role in the regeneration and repair of the nervous system. In fact, FGFR1 and FGFR2 stimulation induces complete neural tissue regeneration in planarians and vertebrate embryos [63]. Moreover, FGFs often synergise with other growth factors and cytokines in the generation of multipotent progenitors, for example, in the zebrafish retina [64]. In adult mammalian species, however, FGFs cannot replace damaged tissue, although stimulation of FGFR signalling assists in adult neurogenesis [65] and promotes neuronal survival after injury [1]. Conversely, expression of dominantnegative FGFR results in increased neuronal vulnerability [66]. The neuroprotective functions of FGFs are at least partially mediated by direct stimulation of neuronal FGFRs and are related to the inhibition of autophagy/protein clearance in a PI3K/AKT/mTOR-dependent manner [67].

In addition to preventing or delaying neuronal cell death, FGFs are involved in the repair of synaptic connections. The formation of new excitatory synaptic contacts is regulated by FGF22, which is expressed in spinal interneurons and long propriospinal neurons [68]. In fact, a lack of FGF22 or targeted deletion of FGFR1 and FGFR2 in the motor cortex reduces synapse formation between corticospinal collaterals and relay neurons and attenuates functional recovery in response to spinal cord injury [69]. FGFR $1 b$ and $2 b$ are required for excitatory and inhibitory presynaptic differentiation in response to FGF22 and FGF7, respectively [70, 71]. Both receptors mediate the excitatory presynaptic response to FGF22, whereas only FGFR2b elicits the inhibitory presynaptic response to FGF7.

FGF7-deficient mice exhibit epileptogenic changes in the hippocampus. This indicates that inhibitory synapse formation may be impaired, resulting in mossy fibre sprouting and enhanced neurogenesis during development [72]. Blocking FGF22 while activating FGF7 signalling may help to alleviate epileptogenesis. In general, it is assumed that FGFs are implicated in both seizure susceptibility and seizure-induced plasticity. It has been suggested that FGF2 favours acute seizures but reduces seizure-induced cell death [73, 74]. In the amyotrophic lateral sclerosis (ALS) model of mutant SOD1 mice, FGF deficiency causes a significant delay in disease onset, less impaired motor function, and prolonged survival when compared with mice with normal FGF2 levels, probably due to an up-regulation of neurotrophic factors such as CNTF and GDNF [75].

FGF2 and FGF20 synergise to increase dopaminergic neuron numbers in stem cell models [3]. FGF20 has been found to be preferentially expressed in the substantia nigra, pars compacta. It stimulates survival of dopaminergic neurons via activation of FGFR1IIIc [76]. In addition, FGF2 facilitates the formation of functional dopaminergic neurons from stem cells $[77,78]$. In the 6-hydroxydopamine lesion model, infusion of FGF20 into the substantia nigra protects against cell death in both the substantia nigra and striatum, and this is accompanied by improved motor function [79]. Moreover, intrastriatal 
expression of FGF2 results in dopaminergic neuron recovery following chemically induced lesions [80].

With regard to Alzheimer's disease, overexpression of FGF2 restores spatial learning, long-term potentiation, and neurogenesis. These effects are probably mediated by FGFR1-activated increases in CD200, the OX-2 membrane glycoprotein that regulates microglial activity and promotes neurite outgrowth and neuronal survival [81]. Furthermore, exogenous FGF2 ameliorates tau pathology and spatial memory deficits by down-regulating the amyloid precursor protein-cleaving enzyme (BACE1) that is involved in the production of amyloid $\beta$ [82]. In primary hippocampal neuron culture, protection against amyloid $\beta$-induced neurotoxicity has been demonstrated to be dependent on the AKT but not the ERK signalling pathway. Interestingly, high molecular weight isoforms of FGF2 are more efficient than those of low molecular weight in this paradigm [83].

Endogenous FGF2 is secreted by neurons upon damage by glutamate or oligomeric amyloid $\beta$. This is followed by enhanced microglial migration and neuroprotection because of increased phagocytosis of neuronal debris via FGFR3 activation involving ERK and Wnt signalling [84]. However, loss of all three FGFRs in astrocytes results in microglia hypertrophy and proliferation [85]. These findings indicate a key role for FGF2 and FGFRs in orchestrating the crosstalk between degenerating neurons, microglia, and astrocytes. They also show that cellular activation and proliferation are distinct and that FGF-dependent processes are induced at different points after injury (Fig. 2).

Glutamate-mediated neuronal damage is observed in the hippocampus following temporal lobe epilepsy. This brain structure is highly dependent on FGFR1 signalling during development via FGF-mediated stimulation of hippocampal progenitor and stem cells [86]. Hippocampal deficits observed in patients with neurodegeneration, trauma, Alzheimer's disease, and in normal ageing may therefore be counteracted by the incorporation of newly born neurons into existing networks. In fact, hippocampal neurogenesis has been observed to facilitate learning and memory in rodents. Adult neurogenesis in the human hippocampus is, however, a heavily debated issue. Recently, neurogenesis has been demonstrated to be limited to early development and childhood [87]. Other groups have observed ongoing neurogenesis in the hippocampus and a modest decline with age by applying improved strategies for the visualisation of neuronal precursor cells [88].

Stimulating neurogenesis through enhanced FGF signalling in the adult hippocampus may therefore be beneficial, particularly since neurogenesis decreases progressively in the brains of Alzheimer's disease-affected patients. It is not yet clear, however, whether intrinsic precursor cell activity or changes in their environment determines such decline. Although FGFs promote the proliferation of cultured adult hippocampal precursor cells, their requirement for in vivo hippocampal neurogenesis in the adult and ageing brain still needs to be demonstrated. Elegant studies including conditional expression of mutated FGFRs have revealed that FGF signalling is clearly required for stem cell maintenance and increased neuron production [89-91]. Moreover, activated FGFR restores age-related decline in neurogenesis to a level found in young adult animals [92].

Neuronal degeneration is often associated with oedema formation and vascular pathology. These are particularly common in ageing and regularly affect hippocampal formation [73]. FGFs exert beneficial effects in some of these conditions, for example, in retinal cell swelling [93] and ischemicreperfusion or hypoxic injury $[94,95]$. FGF1 mixed into fibrin glue as a slow-release carrier reduces ischemia-induced focal brain infarction and attenuates functional deficits. Hippocampal and cortical neuron loss as well as microglial infiltration are also reduced. In addition, FGFs induce upregulation of tight junction proteins via RhoA inhibition, thereby mitigating blood-brain barrier (BBB) breakdown and secondary brain injury [96].

\section{Trauma in the CNS}

Adult axon regeneration across spinal cord injuries and into intact spinal cord tissue generally fails in all higher vertebrates. Only a few growth factors, amongst them FGF1 and FGF2, were shown to promote axonal growth and functional recovery in spinal cord injury (SCI) models $[97,98]$. The observed beneficial effects have been attributed generally to an attenuation of astrogliosis, increased numbers of neuronal progenitors, and/or stimulation of bipolar astrocyte morphology, which result in glial bridge formation guiding regenerating axons across the lesion site [99]. In fact, astrocytes use FGF2 as an auto- and intracrine signal to promote proliferation and structural changes in glial cells via FGFR 1 or FGFR2 signalling. This effect can be enhanced by exogenous FGF2 [100]. FGF2 treatment shortly after spinal cord hemisection results in a significant reduction of TNF $\alpha$ expression at the lesion site, gliosis, and monocyte/macrophage infiltration 2 weeks later. Levels of astrocyte-derived chondroitin sulphate proteoglycans (CSPGs) are also markedly decreased, and functional recovery significantly improved [101]. Interestingly, similar effects were observed in the spinal cord of injured mice lacking Spry4, an endogenous feedback inhibitor of FGF signalling [102].

Recent evidence suggests, however, that FGF signalling is also required for the re-establishment of the non-reactive state of astrocytes following the initial phase after CNS injury. After applying conditional genetic approaches to manipulate FGFRs specifically in adult astrocytes, strong activation was observed in the lesioned neocortex of FGFR1-3 triple knockout mice [85]. Both FGF1 and FGF2 inhibit GFAP expression via FGFR3 signalling [103, 104]. Since the formation of 


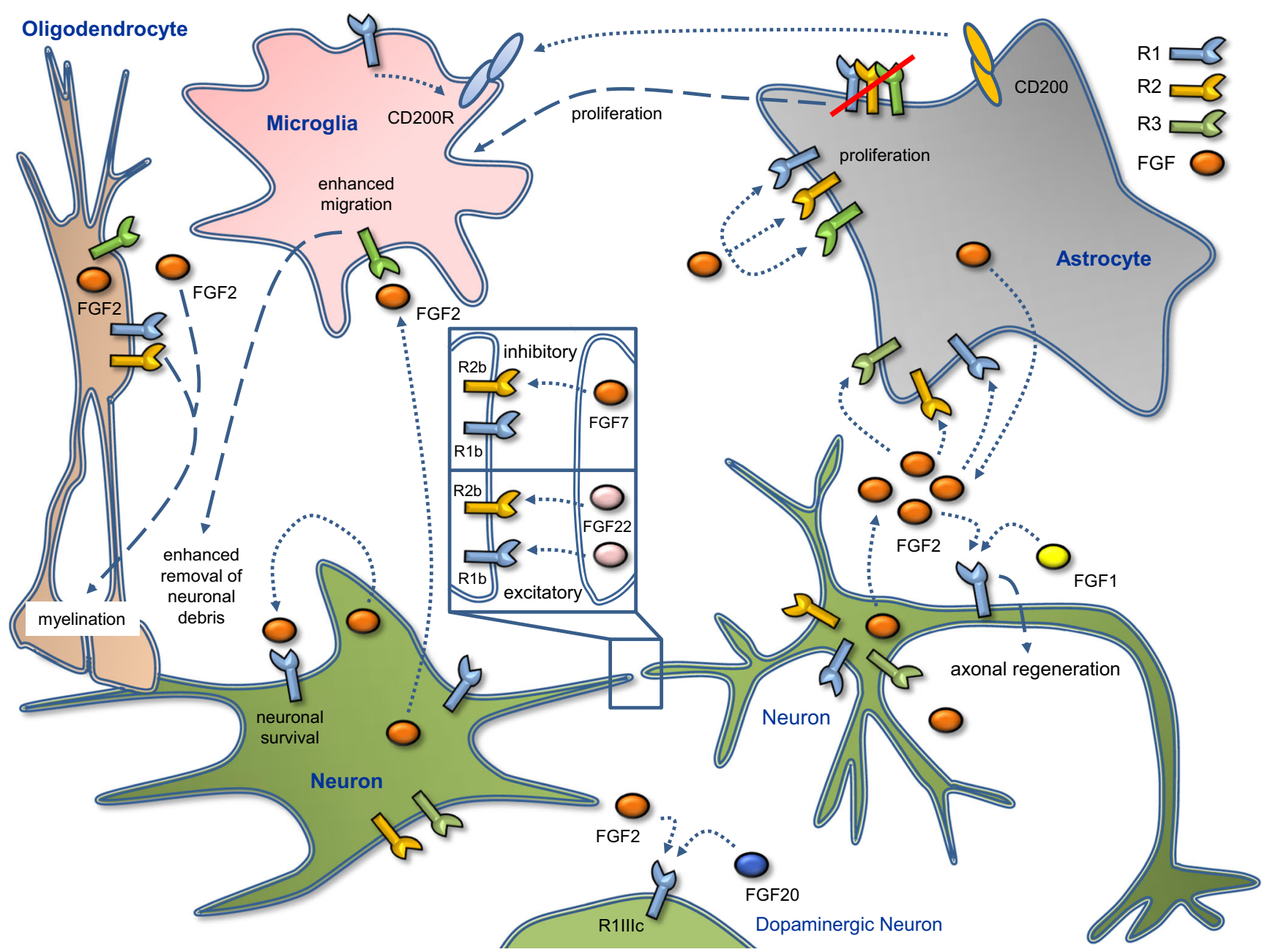

Fig. 2 Key mechanisms of FGF/FGFRs in the nervous system. The central nervous system comprises a large number of functionally and structurally diverse neuronal and glial cell types. The figure depicts model neurons forming synaptic connections as well as oligodendrocytes, astrocytes, and microglia. Modulation of synaptic connections by FGFs (boxed inset): FGF22 regulates the formation of excitatory synapses together with FGFR1b and R2b. Although both are involved in excitatory synapse regulation, inhibitory synapses are regulated by FGF7 via FGFR2b only. FGF2 and 20 synergise to regulate differentiation of dopaminergic neurons by using FGFR1IIIc as the receptor (FGF20 also binds to FGFR1IIIc in other neurons). When secreted by neurons, FGF2 enhances microglia activation, leading to increased removal of neuronal debris in case of neuronal damage. Moreover, FGF2 restores spatial learning, long-term potentiation, and neurogenesis in Alzheimer's disease. Mechanistically, FGFR1 regulates CD200, which in turn mediates microglia responses and neurite outgrowth. This factor also feeds back by activation of FGFR1. Axonal growth and regeneration is stimulated mainly by FGF1 and FGF2. FGF2 secreted by neurons stimulates astrocytes via FGFR1-3 activation. Signalling from astrocytes to oligodendrocytes is accomplished by FGF2 influencing the survival and proliferation of oligodendrocyte precursor cells (OPCs). FGFR1 and R2 regulate myelin thickness and gene expression. For references, see text astrocytic scars clearly inhibits axon regeneration in the CNS, the reversal of the active state in astrocytes (probably involving changes in heparin sulphatation [105]) is likely to contribute to the positive effects of FGF1 and FGF2 on functional recovery after axotomy of intrinsic spinal cord or peripheral axons projecting into the CNS [91, 106-108].

A recent study [109] provided convincing evidence for a reversal of the dogma that adult CNS axons do not regenerate over long distances, by overcoming three obstacles simultaneously. The authors demonstrated that enhancing the intrinsic neuronal growth machinery and providing a supportive extracellular matrix via stimulation of FGF signalling, together with the application of chemoattractive cues, results in robust and successful axon regrowth across at least one spinal segment after complete spinal cord injury in rodents. In this model, osteopontin, IGF1, and CNTF were applied before injury. Growth-supportive substrates were induced by a combination of EGF and FGF2, which increased astrocytic proliferation as well as laminin, collagen, and fibronectin production inside the lesions. Then, propriospinal axons were attracted with GDNF delivered from biomaterial depots. All of these steps must be performed in combination to stimulate axon regeneration significantly, i.e. by a factor of around 100 . Treatment with FGFs alone did not support axonal growth 
through astrocyte scars and across the lesion core into spared neural tissue. The combined approach resulted in the formation of terminal synapses and the re-establishment of electrophysiological conduction capacity [109].

Other studies confirm that stimulation of FGFR1 signalling alone is not sufficient to promote axon regeneration in the CNS. Up-regulation of FGFR1 in neurons projecting into the corticospinal tract (CST) does not enhance axon outgrowth. Injection of AAV serotype 1 overexpressing FGFR1 in a rat model of unilateral pyramidotomy did not increase sprouting of intact contralateral CST axons with overexpressed FGFR1, nor was it accompanied by functional improvements over control AAV injected animals [100]. Overexpression of FGFR1 in cultured cerebellar granule neurons even resulted in decreased neurite outgrowth. It is possible that key adaptor proteins, such as FRS2, are sequestered away from neurotrophic receptors promoting strong axon outgrowth, such as TrkA [110]. It has been shown previously that FGF2 exerts inhibitory effects on neurite outgrowth of cerebellar neurons plated on cortical astrocytes [111]. In addition, FGF1 and FGF2 may even interact with inhibitory receptors, such as the Nogo-66 receptor 1 (NgR1) [112].

$\mathrm{NgR} 1$ is a member of the Nogo receptor family implicated in the binding of myelin inhibitors and chondroitin sulphate proteoglycans [113]. It is part of a multi-component receptor complex comprising Lingo-1, p75, or TROY, which induces activation of the small GTPase RhoA, a well-known pathway involved in growth cone collapse and neurite outgrowth inhibition [114]. Interestingly, FGF2-dependent neurotrophic effects such as neuronal differentiation of $\mathrm{PC} 12$ cells and axonal branching in cortical neuron cultures are fully blocked by the ectopic overexpression of NgR1. Direct interaction between the two receptors could not be demonstrated; however, highaffinity binding of FGF2 to NgR1 was observed, suggesting that FGF family members also act as ligands at completely unrelated receptors [112].

\section{Nerve Injury in the PNS}

In the peripheral nervous system (PNS), axons do regenerate in the absence of exogenous growth factor support, provided that the proximal nerve stump containing the severed axons is connected to its distal counterpart. FGF1, FGF2, FGF7, and FGFR3 are all rapidly up-regulated in the lesioned nerve and in corresponding ganglia after axotomy $[115,116]$. FGF2 prevents apoptosis of sensory neurons when applied directly to the transected sciatic nerve [117]. FGF1 and FGF2 have both been shown to improve nerve regeneration across a collagenfilled nerve conduit $[118,119]$. In fact, FGF2 is one of the most promising growth factor with regard to clinically relevant muscle re-innervation, because it induces neurite elongation of motor axons similarly to GDNF [120].
Channels filled with Schwann cells overexpressing the high molecular weight (HMW) isoforms of FGF2 are particularly useful in promoting nerve regeneration $[121,122]$. Low molecular weight $(18 \mathrm{kD})$ FGF2 released from transduced Schwann cells also accelerates regeneration and functional recovery when it is used to repair the transected sciatic nerve [123]. Because of their effect on the mitogenesis of mesoderm- and neuroectoderm-derived cells, it is assumed that FGFs support axonal regeneration mainly via increased proliferation of Schwann cells and enhanced angiogenesis [118]. Yet, direct trophic effects of FGF2 isoforms on primary neurons are observed as well. Nevertheless, adult sensory neurons must be sensitised before FGF treatment by prior axotomy in vivo. In response to such a 'pre-conditioning' lesion, i.e. a sciatic nerve transection 1 week before extraction of the lumbar ganglia, FGF2 isoforms stimulate axonal elongation preferably [124]. This effect can be completely blocked by SU5402, a specific FGFR antagonist, and it is mediated by ERK and PI3K activation. Naïve, untreated sensory neurons exhibit only a little FGFR1 and FGFR2 at their surface, suggesting that axotomy-induced receptor upregulation may be involved in the regenerative response.

Hence, FGF2 does not exert prominent effects on peripheral axon outgrowth if neurons have not been pre-lesioned. However, increasing FGFR1 levels by overexpression, inhibition of degradation, or promotion of receptor recycling all stimulate peripheral axon regeneration [55, 125]. Additional treatment with the protease inhibitor leupeptin further increases outgrowth $[57,58]$. FGFR3 stimulation induces the opposite response, since FGFR3-deficient mice reveal reduced neuronal apoptosis in response to nerve transection [126]. Transgenic mice expressing high levels of FGF2 reveal faster axon regeneration, probably as a result of combined effects on Schwann cell proliferation, delayed myelination, and on axons directly [127]. Moreover, intramuscular injections of FGF2 increase the amplitude of compound muscle action potentials, wet muscle weight, and motor endplate density [128].

Enhanced FGF signalling has also been shown to be beneficial in response to facial nerve injury [129]. The already poor recovery of regenerating facial axons is further compromised in FGF2 knock-out mice. However, FGF2-deficient animals exhibit no difference in the number of regenerating axons in the sciatic nerve. In fact, faster recovery of mechanosensory (but not of motor) function following sciatic nerve crush was observed, suggesting compensatory mechanisms in the lesioned peripheral nervous system of global FGF2 knock-outs [130].

Our own investigations on FGFR signalling antagonists like Sprouty proteins corroborate the positive effects of FGFs on axon regeneration. Primary sensory or hippocampal neurons dissociated from Sprouty 2 knock-out mice or transfected with shRNAs against Sprouty2 and Sprouty4 
reveal significantly enhanced axon outgrowth [131-133]. Following sciatic nerve crush, more myelinated axons regenerate in heterozygous Sprouty2 knock-out mice, and this is accompanied by faster recovery of sensorimotor performance and increased expression of the regeneration-associated GAP43 protein [133].

As stated above, FGFRs interact with other membrane components that may affect neuronal survival and even axon regeneration. For example, FGFR1 is required for neurite outgrowth stimulated by CAMs (PSA-NCAM, $\alpha 7$ integrin, and $\mathrm{N}$-cadherin) in neurons and in neuron-like cell lines [61, 134-136]. NCAM/FGFR1 receptor complexes could be particularly relevant for motor axon regeneration in trans: FGFR1 is found at the plasma membrane of Schwann cells, and polysialylated (PSA)-NCAM (but not FGFR1) is localised at the membrane of elongating motor axons during the early phase of regeneration. This hypothesis is further supported by the demonstration of an increased interaction of FGFR 1 and PSA-NCAM following FGF2 treatment [120]. Moreover, FGFR and neurotrophin receptor (Trk) signalling is codependent as well. Rat pheochromocytoma (PC12) cells expressing dominant negative FGFR exhibit reduced NGFinduced process formation and autophosphorylation of FGFRs. Selective FGFR inhibitors or oligonucleotides that interfere with receptor binding completely block neurite outgrowth induced by NGF in this cell line [137].

With regard to the possible interaction with inhibitory signalling pathways, previous studies by the Schwab group have suggested that the Nogo/NgR system is not only relevant for the CNS but for the PNS as well. Axonal regeneration and functional recovery are impaired following sciatic nerve crush in transgenic mice overexpressing Nogo-A in Schwann cells [138]. By contrast, sciatic nerve regeneration is enhanced in NgR1 knock-out mice (authors' observation). Importantly, NgR1 is expressed in adult DRG sensory neurons and in motoneurons $[139,140]$. However, there is no evidence of a potential cross-talk between NgR1/p75/RhoA and FGF signalling in the PNS yet, although FGF2 has been demonstrated to act as potent inhibitor of RhoA in primary neuron cultures [141].

With regard to lesion-induced neuropathic pain, FGF7 may play a role in injury-induced nociception. It is localised in the large dense-core vesicles (LDCVs) of small-diameter primary sensory neurons and may be transported to the dorsal spinal cord [142]. FGF7 increases the amplitude of excitatory postsynaptic current evoked by stimulating the sensory afferent fibres in spinal cord slices. Intrathecally applied FGF7 potentiates a formalin-induced acute nociceptive response, while it is diminished in FGF7 knock-out mice. Mice deficient in FGF2 or FGFR1/FGFR2 exhibit decreased thermal pain sensitivity accompanied by neuropathy of unmyelinated axons in the dorsal spinal cord $[143,144]$. Furthermore, continuous intrathecal infusion of FGFR1 inhibitors reduces neuropathic pain-related behaviour in the partial sciatic nerve lesion model via inhibition of p38 MAPK [145].

\section{Demyelination in the CNS}

In the CNS, oligodendrocytes are required for myelination during development and in demyelinating disease. FGFR 1 expression in these cells increases as the lineage progresses from oligodendrocyte precursor cells (OPCs) to mature oligodendrocytes. FGF2 and FGFR2 are also found in terminally differentiated oligodendrocytes [146]. Astrocyte-derived FGF2 positively influences the survival and proliferation of OPCs [147]. Conditional ablation of FGFR1 and R2 leads to the down-regulation of myelin gene expression, reduced myelin thickness, and axonal degeneration as knock-out mice age $[148,149]$. FGFR3 is expressed in OPCs as well; however, FGFR3-deficient mice exhibit no changes in OPC proliferation rates [150].

Demyelination causes severe neurological deficits that are partially reversed by the spontaneous remyelination of axons by oligodendrocytes. Although the CNS is isolated from the peripheral milieu by the blood-brain barrier, remyelination can be triggered by peripheral factors that leak into the CNS after injury, including FGFs. Various FGFs are elevated in autoimmune diseases of the brain, such as multiple sclerosis: FGF1 in remyelinated lesions, FGF2 in active lesions and in the cerebrospinal fluid, FGF9 in active demyelinated lesions, and FGF21 in activated microglia or macrophages [151-153]. Intraventricular delivery of FGF2 induces severe disruption of mature oligodendrocytes, a marked loss of myelin, and aberrant accumulation of immature oligodendrocytes with a premyelinating phenotype [154]. Interestingly, the relative concentrations of the extracellular matrix protein Anosmin-1 and FGF2 in human MS lesions appears to be important for OPC migration through their interactions with FGFR1. This may have consequences for remyelination of lesioned axons because Anosmin-1 inhibits the effects of FGF2 on cellular migration [155-157].

FGF9 (also termed glia activating factor) is expressed by neurons and glia [158]. Like FGF2, FGF9 suppresses myelin protein synthesis by differentiating OPCs [159]. In multiple sclerosis (MS) lesions, FGF9 has been demonstrated to act indirectly, i.e. via the initiation of a complex astrocytic response that compromises remyelination [151]. By contrast, circulating FGF21, a member of the endocrine FGF family (expressed in the pancreas), stimulates OPC proliferation through interactions with $\beta$-klotho, an essential co-receptor of endocrine FGFs, in lysophosphatidylcholine (LPC)-induced lesions [160]. OPCs express $\beta$-klotho, the inhibition of which prevents increased OPC proliferation and remyelination.

Another level of complexity is introduced by the action of FGF1 and FGF2 in acute versus chronic MS lesions. FGF2 
and FGFR1 levels are higher in MS patients than in controls, and a difference between relapse patients with higher FGF2 levels and those in remission is observed as well [161]. FGFR1 and FGFR2 double mutant mice exhibit hypomyelination in the chronic cuprizone model, indicating that FGF signalling (presumably via PI3K/AKT) is necessary for remyelination [162]. However, other studies have found the opposite, i.e., increased numbers of oligodendrocytes and improved remyelination of cuprizone-induced lesions or less myelin and axonal loss in $\mathrm{MOG}_{35-55}$-induced $\mathrm{EAE}$ in mice lacking FGF2 or FGFR1 [163-167]. This discrepancy may be due to the complexity of FGF signalling in multiple responses to injury and stress.

In experimental autoimmune encephalomyelitis (EAE), a model for MS, overexpression of FGF2 leads to enhanced remyelination and reduced axonal damage [168, 169]. Conversely, in the $\mathrm{MOG}_{35-55}$-induced EAE model of MS, FGF2 deficiency results in a more severe disease course, increased infiltration of lymphocytes and macrophages, and reduced remyelination [170]. By contrast, viral-mediated FGF2 overexpression results in less disease severity via inhibition of lymphocyte/macrophage infiltration [168]. FGF2 treatment clearly interferes with inflammation by reducing macrophages, microglia, and CD8 T-cells and limiting CD44mediated leukocyte migration $[168,171,172]$.

\section{Brain Tumour Formation}

FGFRs are commonly overexpressed in many types of cancer. High levels of FGFR1 are associated with better overall survival in peripheral nerve sheath sarcomas [173], while activating mutations in the FGFR1 kinase domain have been found in a subset of glioblastoma patients with poor prognosis [174]. FGFR2 is expressed at lower levels in high-grade gliomas, which correlates with higher proliferation and lower survival rates [175]. These grade IV malignant gliomas are amongst the most lethal human cancers, because they are resistant to neurosurgery, cytotoxic chemotherapy, and radiation [176]. Most patients present with primary glioblastoma multiforme associated with irregular signalling of epidermal growth factor (EGF) receptors or mutated PTEN (phosphatase and tensin homolog). Combined RAS/AKT signalling and PTEN deficiency have been shown to act as the main drivers of these tumours [177]. Regulators of ERK signalling, such as the Sprouty proteins, also play an important role in glioma proliferation [178].

High levels of FGF1 and FGF2 have been detected in glioma tissue relative to the normal brain [179]. Whereas expression of FGFR 1 is low in normal white matter, its synthesis is dramatically increased in malignant astrocytic tumours [180]. Nuclear FGFR1 contributes to increased proliferation of glioma cells [19]. The blockade of FGF signalling by various means, amongst them FGF2 antibodies, siRNAs against
FGFR1, or treatment with the FGFR/VEGFR inhibitor PD173074, reveals small but significant growth inhibitory effects in glioma cell lines [181, 182]. FGF inhibitors stimulate apoptosis, inhibit glioblastoma invasion, and suppress angiogenesis [183]. Down-regulation of FGF2 potentiates the effect of temozolomide (TMZ), an oral alkylating agent, by inhibiting proliferation and migration, blocking the cell cycle in G0/G1, and promoting apoptosis [184]. However, the efficient treatment of brain tumours with antibodies, siRNAs, or pharmacological inhibitors remains a challenge (see Therapeutic Approaches below).

Glioblastoma is also one of the most highly vascularised cancers. Therefore, inhibition of FGF activity, for example, by overexpressing dominant-negative FGFR1, may constitute a therapeutic strategy for disrupting angiogenesis-dependent signals required for glioma growth and invasion [185]. FGF2 promotes angiogenesis directly by activating the proliferation and migration of endothelial cells and indirectly by upregulating urokinase-type plasminogen activator, which also leads to cell migration [186]. Furthermore, secretion of FGF2 by glioma cells enhances the blood-brain barrier function of endothelial cells, which may contribute to drug resistance [187]. Interestingly, recent data suggest that FGFR1 inhibitors also decrease resistance to radiotherapy, a widespread problem in glioblastoma [188].

\section{FGFs in Psychiatric Disorders}

Over the years, it has become clear that FGF2 may act as key factor in neuropsychiatric syndromes via activation of FGFR 1 [3, 189-191]. The proposed functions range from memory enhancing to anti-depressant and anxiolytic functions. In fact, FGF2 is down-regulated in rats showing high spontaneous anxiety. Knockdown of hippocampal FGF2 activity increases anxiety in naïve rats, and FGF2 treatment reduces anxiety in highly anxious rats [192]. However, mice with genetic ablation of FGF2 isoforms do not show alterations of anxiety-like stress susceptibility [193]. It should be noted, however, that other growth factors (BDNF and IGF-1) exert similar neuromodulatory effects as FGF2 on anxiety-related behaviour, as do genetic and environmental factors.

Traditional anxiolytics interfere with long-term extinction of fear memories. By contrast, chronic extinction is augmented by FGF2 that reduces the likelihood of exhibiting a relapse of extinguished fear in a new environment or following stress. Interestingly, early life treatment with FGF2 may decrease anxiety-like behaviour in adulthood, which probably involves an interaction between FGF receptors and adenosine A2 receptors or dopamine D2 receptors [194]. Furthermore, epigenetic mechanisms may be involved, such as regulation of noncoding RNAs, histone modifications, or DNA methylation [3]. FGF2 promotes the association of trimethylated histone 
protein $\mathrm{H} 3$ at lysine 9 (H3K9me3) at its own promoter [195]. Commonly used bipolar disorder drugs, such as valproate and lithium chloride, have been shown to inhibit histone deacetylases (HDACs) and to increase FGF1 expression [196].

Changes in FGFR levels and genetic variations of FGFR2 have been implicated in the pathomechanisms of schizophrenia [197]. Serum levels of FGF2 are increased in medicated schizophrenia patients and in non-medicated patients exhibiting negative symptoms [198]. FGF signalling disturbances in mood disorders might be indirect, since the disruption of schizophrenia-associated proteins, such as the neuronal PAS domain protein 3 (NPAS3), correlates with a dramatic reduction in FGFR 1 mRNA, and NPAS3 deficiency behaviourally resembles FGFR1 knock-out mice [199]. Moreover, the phenotype of FGFR-deficient mice is reminiscent of other animal models for schizophrenia and mood disorders, for example, of knock-outs for disruption in schizophrenia 1 (DISC1), BDNF, and NRG1 [191]. Interestingly, nuclear FGFR1 has been implicated in the disease pathogenesis of schizophrenia. Neuron-committed cells from patients overexpressing FGFR1 reveal an association of nuclear FGFR1 with a large number of genes dysregulated in schizophrenia [27].

FGF signalling is clearly disturbed in individuals with major depressive disorder (MDD). Levels of FGF1, FGF2, FGFR2, and FGFR3 decrease in cortical areas, while FGF9 and FGF12 are elevated in the anterior cingulate and dorsolateral prefrontal cortex of depressive patients [200]. Ubiquitously found NG2 glial cells (precursors for myelinating oligodendrocytes) have been shown to secrete FGF2 during chronic stress, which may prevent glutamate abnormalities and maladaptive depressive behaviour [201]. Direct relationships were suggested when the intracerebroventricular injection of FGF2 resulted in antidepressant effects, which were also observed after FGF2 infusion into the prefrontal cortex in chronic unpredictable stress models of depression [202]. Notably, FGF2 may have indirectly enhanced neuronal activity by the stimulation of astrocyte proliferation, which is reduced in rodent depression models.

Elevated FGF2 levels may also play a role in the therapeutic effects of tricyclic antidepressants and selective serotonin re-uptake inhibitors [203]. The low and high molecular weight isoforms of FGF2 increase in response to monoamine oxidase inhibitor treatment in cortical astrocytes [204], and antidepressive treatments in rodents elevated FGF2 expression in the hippocampus and cerebral cortex [203, 205]. Inflammatory reactions such as microglia activation and proliferation, which accompany depressive-like behaviours in LPS models, are ameliorated by neuron-derived endogenous FGF2 [171] or by FGF2 infusions [206]. FGF22 is putatively also involved in regulating affective behaviour. FGF22 knock-out mice exhibit depressive symptoms such as longer duration of floating, increased immobility in the tail suspension test, and a decreased preference for sucrose [207].

In animal models of drug use and addiction, FGF2 expression is increased in reward-related infralimbic/medial prefrontal cortex areas, and its neutralisation facilitates extinction of cocaine seeking [208]. Cocaine blocks the re-uptake of dopamine, and the auto-oxidation of dopamine results in freeradicals as by-products [209], which in turn increase FGF2 expression in astrocytes [30]. FGF2 is required for amphetamine-induced sensitisation [210], dendritic growth in dopaminergic neurons, and reductions in intrinsic excitability [211]. These effects are probably mediated not only by FGF2 but also by a cocktail of growth factors that arbitrate maladaptive stimulant induced alterations in neuronal function and structure.

\section{Therapeutic Approaches}

FGFs display a poor blood-brain barrier penetration and have a short half-life. They are vulnerable to proteolytic cleavage events resulting in their inactivation in various body fluids. A recent study demonstrated that a protein delivery coacervate can be prepared that controls FGF2 release and maintains its bioactivity by binding FGF2 via charge interaction consisting of polycation-polyethylene argininylaspartatediglyceride (PEAD) and heparin [212]. Furthermore, biodegradable micro-osmotic pumps based on microelectromechanical system (MEMS) technology have been developed for long-term controlled release of FGF2 [213]. Clearly, novel approaches including small non-peptidergic FGF mimetics will be required for the treatment of central and peripheral nervous system disorders.

Stimulants of FGFR and NCAM, such as the FGF-derived dekafin peptides, will be particularly useful in promoting tissue repair $[214,215]$. It will be interesting to determine if these dendrimers might also be beneficial in normalising cognitive and social behaviour by their influence on the excitation/inhibition balance in the brain. Furthermore, FGFdendrimer-based targeted delivery of drugs through FGFR may be a useful technology to target tumour cells or other FGFR expressing cells [216]. Novel biomaterials such as nontoxic and chemically inert hydrogels provide ideal scaffolds for the ingrowth of regenerating axons. Recently, FGF2 containing HEMA-MOETACL hydrogels were demonstrated to deliver FGF to the injured spinal cord in a localised and sustained manner [217]. Two months after implantation, the hydrogel was surrounded by an acellular vascular matrix consisting of glycosaminoglycan (GAG) and elastic/collagen fibres that promoted FGF-enhanced adhesion and migration of various cells types, resulting in nervous tissue regeneration and functional recovery in the paralysed hindlimbs of rats with complete spinal cord injury. 
More recent developments include genetic approaches, for example, neuronal or glial FGF/FGFR transfer via lentiviral vectors (LVs). Gene therapy provides a useful tool for the specific down-regulation or knock-out of neuronal targets, since efficient siRNA treatments and viral gene transfer of shRNAs are now available for humans. Gene replacement therapy has been demonstrated to promote survival of patients with spinal muscular atrophy (SMA) following a single intravenous infusion of adeno-associated virus 9 (AAV9) containing cDNA coding for SMN [218]. LVs are even more useful for in vivo applications than AAVs because of their efficiency in gene delivery and their excellent safety profile. Moreover, in contrast with retroviral vectors, LVs do not depend on active division of the cell to be transduced and produce only minimal alteration in cellular physiology [219]. Alternatively, organically modified silica (ORMOSIL) nanoparticles may be used as nonviral vectors for efficient in vivo gene delivery. Nucleus-targeting FGFR1 was successfully transfected with this method [220].

\section{Conclusions}

The intricate relationship between oligodendrocytes and Schwann cells and central and peripheral axons, respectively, as well as the close association of ramified astrocytic or microglial processes with neuronal perikarya, neurites, and synapses represent the morphological basis for all FGFRdependent signalling processes in neuronal and glial cells. More than 10 members of the FGF family function in these spatio-temporal domains, including membrane and nuclear compartments, to regulate transcriptional, post-transcriptional, and post-translational molecular events underlying instant changes in behaviour, long-lasting tissue repair, and axon regeneration. The effects of FGFs are clearly different from other neuronal growth factor families that act in the developing and adult brain. First, they strongly involve glial elements, and, second, they interact with several unrelated receptors via direct physical interaction or formation of heteromeric receptor complexes.

Currently, it is not possible to conclude with certainty whether the neurochemical and morphological alterations induced by FGFR signalling represent causes, consequences, epiphenomena, or a combination of those in the various pathological processes discussed here. Therefore, it is often not clear whether modulators of FGFRs would result in successful treatment that interferes with disease defining pathomechanisms. They could also alleviate symptoms or modify secondary, perhaps even beneficial aspects of brain disorders as exemplified by the negative effects of endogenous FGF2 in experimental models of amyotrophic lateral sclerosis [75]. Hence, the specific cellular context of a given pathology involving primarily glial and/or neuronal mechanisms will decide whether therapeutic interference with FGFRs is indicated or not.

Code Availability Not applicable

Author Contribution All authors whose names appear on the submission:

(1)Made substantial contributions to the conception or design of the work; or the acquisition, analysis, or interpretation of data; or the creation of new software used in the work

(2)Drafted the work or revised it critically for important intellectual content

(3)Approved the version to be published

(4)Agreed to be accountable for all aspects of the work in ensuring that questions related to the accuracy or integrity of any part of the work are appropriately investigated and resolved

Funding Open access funding provided by University of Innsbruck and Medical University of Innsbruck.

Data availability Not applicable

\section{Declarations}

Consent to Participate Not applicable.

Consent for Publication All authors whose names appear on the submission agreed the version to be published.

Competing Interests The authors declare no competing interests.

Open Access This article is licensed under a Creative Commons Attribution 4.0 International License, which permits use, sharing, adaptation, distribution and reproduction in any medium or format, as long as you give appropriate credit to the original author(s) and the source, provide a link to the Creative Commons licence, and indicate if changes were made. The images or other third party material in this article are included in the article's Creative Commons licence, unless indicated otherwise in a credit line to the material. If material is not included in the article's Creative Commons licence and your intended use is not permitted by statutory regulation or exceeds the permitted use, you will need to obtain permission directly from the copyright holder. To view a copy of this licence, visit http://creativecommons.org/licenses/by/4.0/.

\section{References}

1. Reuss B, BuH O (2003) Fibroblast growth factors and their receptors in the central nervous system. Cell Tiss Res 313(2):139-157

2. Guillemot F, Zimmer C (2011) From cradle to grave: the multiple roles of fibroblast growth factors in neural development. Neuron 71(4):574-588

3. Turner CA, Eren-Kocak E, Inui EG, Watson SJ, Akil H (2015) Dysregulated fibroblast growth factor (FGF) signaling in neurological and psychiatric disorders. Sem Cell Dev Biol 53:136-143

4. Li X, Wang C, Xiao J, McKeehan WL, Wang F (2016) Fibroblast growth factors, old kids on the new block. Sem Cell Dev Biol 53: 155-167

5. Eckenstein FP, Shipley GD, Nishi R (1991) Acidic and basic fibroblast growth factors in the nervous system: distribution and differential alteration of levels after injury of central versus peripheral nerve. J Neurosci 11:412-419 
6. Nickel W (2011) The unconventional secretory machinery of fibroblast growth factor 2. Traffic 12(7):799-805

7. Wesche J, Malécki J, Widlocha A, Skjerpen CS, Claus P, Olsnes S (2006) FGF-1 and FGF-2 require the cytosolic chaperone Hsp90 for translocation into the cytosol and the cell nucleus. J Biol Chem 281(16):11405-11412

8. Arnaud E, Touriol C, Boutonnet C, Gensac MC, Vagner S, Prats H, Prats AC (1999) A new 34-kilodalton Isoform of human fibroblast growth factor 2 is cap dependently synthesized by using a non-AUG start codon and behaves as a survival factor. Mol Cell Biol 19(1):505-514

9. Claus P, Doring F, Gringel S, Muller-Ostermeyer F, Fuhlrott J, Kraft T, Grothe C (2003) Differential intranuclear localization of fibroblast growth factor-2 isoforms and specific interaction with the survival of motoneuron protein. J Biol Chem 278(1):479-485

10. Prats H, Kaghad M, Prats AC, Klagsbrun M, Lélias JM, Liauzun P, Chalon P, Tauber JP et al (1989) High molecular mass forms of basic fibroblast growth factor are initiated by alternative CUG codons. Proc Natl Acad Sci 86(6):1836-1840

11. Förthmann B, Aletta JM, Lee YW, Terranova C, Birkaya B, Stachowiak EK, Stachowiak MK, Claus P (2015) Coalition of nuclear receptors in the nervous system. J Cell Physiol 230(12):2875-2880

12. Ornitz DM, Itoh N (2015) The fibroblast growth factor signaling pathway. WIREs Dev Biol 4(3):215-266

13. Regeenes R, Silva PN, Chang HH, Arany EJ, Shukalyuk AI, Audet J, Kilkenny DM, Rocheleau JV (2018) Fibroblast growth factor receptor 5 (FGFR5) is a co-receptor for FGFR1 that is upregulated in beta-cells by cytokine-induced inflammation. J Biol Chem 293(44):17218-17228

14. Goetz R, Mohammadi M (2013) Exploring mechanisms of FGF signalling through the lens of structural biology. Nat Rev Mol Cell Biol 14(3):166-180

15. Kalinina J, Dutta K, Ilghari D, Beenken A, Goetz R, A-á E, Cowburn D, Mohammadi M (2012) The alternatively spliced acid box region plays a key role in FGF receptor autoinhibition. Structure 20(1):77-88

16. Brewer JR, Mazot P, Soriano P (2016) Genetic insights into the mechanisms of FGF signaling. Genes Dev 30(7):751-771

17. Maher PA (1996) Nuclear translocation of fibroblast growth factor (FGF) receptors in response to FGF-2. J Cell Biol 134(2):529-536

18. Reilly JF, Maher PA (2001) Importin beta-mediated nuclear import of fibroblast growth factor receptor: role in cell proliferation. $\mathrm{J}$ Cell Biol 152(6):1307-1312

19. Stachowiak EK, Maher PA, Tucholski J, Mordechai E, Joy A, Moffett J, Coons S, Stachowiak MK (1997) Nuclear accumulation of fibroblast growth factor receptors in human glial cellsassociation with cell proliferation. Oncogene 14(18):2201-2211

20. Stachowiak MK, Maher PA, Stachowiak EK (2007) Integrative nuclear signaling in cell development - a role for FGF receptor-1. DNA Cell Biol 26(12):811-826

21. Stachowiak MK, Birkaya B, Aletta J, Narla S, Benson CA, Decker B, Stachowiak EK (2014) Nuclear FGF receptor-1 and CREB binding protein - an integrative signaling module. J Cell Physiol 230(5):989-1002

22. Chioni AM, Grose R (2012) FGFR1 cleavage and nuclear translocation regulates breast cancer cell behavior. J Cell Biol 197(6):801-817

23. Peng H, Myers J, Fang X, Stachowiak EK, Maher PA, Martins GG, Popescu G, Berezney R et al (2002) Integrative nuclear FGFR1 signaling (INFS) pathway mediates activation of the tyrosine hydroxylase gene by angiotensin II, depolarization and protein kinase C. J Neurochem 81(3):506-524

24. Lee YW, Stachowiak EK, Birkaya B, Terranova C, Capacchietti M, Claus P, Aletta JM, Stachowiak MK (2013) NGF-induced cell differentiation and gene activation is mediated by integrative nuclear FGFR1 signaling (INFS). PLoS ONE 8(7):e68931

25. Baron O, Förthmann B, Lee Y-W, Terranova C, Ratzka A, Stachowiak EK, Grothe C, Claus P et al (2012) Cooperation of nuclear fibroblast growth factor receptor 1 and Nurr1 offers new interactive mechanism in postmitotic development of mesencephalic dopaminergic neurons. J Biol Chem 287(24):19827-19840

26. Horbinski C, Stachowiak EK, Chandrasekaran V, Miuzukoshi E, Higgins D, Stachowiak MK (2002) Bone morphogenetic protein7 stimulates initial dendritic growth in sympathetic neurons through an intracellular fibroblast growth factor signaling pathway. J Neurochem 80(1):54-63

27. Narla ST, Lee YW, Benson CA, Sarder P, Brennand KJ, Stachowiak EK, Stachowiak MK (2017) Common developmental genome deprogramming in schizophrenia - role of Integrative Nuclear FGFR1 Signaling (INFS). Schizophr Res 185:17-32

28. Ornitz DM, Xu J, Colvin JS, McEwen DG, MacArthur CA, Coulier F, Gao G, Goldfarb M (1996) Receptor specificity of the fibroblast growth factor family. J Biol Chem 271(25):1529215297

29. Zhang X, Ibrahimi OA, Olsen SK, Umemori H, Mohammadi M, Ornitz DM (2006) Receptor specificity of the fibroblast growth factor family. The complete mammalian FGF family. J Biol Chem 281(23):15694-15700

30. Gonzalez AM, Berry M, Maher PA, Logan A, Baird A (1995) A comprehensive analysis of the distribution of FGF-2 and FGFR1 in the rat brain. Brain Res 701(1-2):201-226

31. Richtsmeier JT, Flaherty K (2013) Hand in glove: brain and skull in development and dysmorphogenesis. Acta neuropathol 125(4): 469-489

32. Coleman SJ, Bruce C, Chioni AM, Kocher HM, Grose RP (2014) The ins and outs of fibroblast growth factor receptor signalling. Clin Sci 127(4):217-231

33. Bryant MR, Marta CB, Kim FS, Bansal R (2009) Phosphorylation and lipid raft association of fibroblast growth factor receptor-2 in oligodendrocytes. Glia 57(9):935-946

34. Simons K, Toomre D (2000) Lipid rafts and signal transduction. Nat Rev Mol Cell Biol 1(1):31-39

35. Doherty P, Walsh FS (1996) CAM-FGF receptor interactions: a model for axonal growth. Mol Cell Neurosci 8(2-3):99-111

36. Francavilla C, Cattaneo P, Berezin V, Bock E, Ami D, de Marco A, Christofori G, Cavallaro U (2009) The binding of NCAM to FGFR1 induces a specific cellular response mediated by receptor trafficking. J Cell Biol 187(7):1101-1116

37. Dijaz-Balzac CA, Lazaro-Pena MI, Ramos-Ortiz GA, Bülow HE (2015) The adhesion molecule KAL-1/anosmin-1 regulates neurite branching through a SAX-7/L1CAM-EGL-15/FGFR receptor complex. Cell Reports 11(9):1377-1384

38. Eswarakumar VP, Lax I, Schlessinger J (2005) Cellular signaling by fibroblast growth factor receptors. Cytok Growth Fact Rev 16 : 139-149

39. Del Piccolo N, Sarabipour S, Hristova K (2016) A new method to study heterodimerization of membrane proteins and its application to fibroblast growth factor receptors. J Biol Chem. 292(4):1288-1301

40. Sarabipour S, Hristova K (2016) Mechanism of FGF receptor dimerization and activation. Nat Commun 7:10262

41. Xu H, Lee KW, Goldfarb M (1998) Novel recognition motif on fibroblast growth factor receptor mediates direct association and activation of SNT adapter proteins. J Biol Chem 273(29):17987-17990

42. Wang JK, Xu H, Li HC, Goldfarb M (1996) Broadly expressed SNT-like proteins link FGF receptor stimulation to activators of Ras. Oncogene 13(4):721-729

43. Ong SH, Lim YP, Low BC, Guy GR (1997) SHP2 associates directly with tyrosine phosphorylated p90 (SNT) protein in 
FGF-stimulated cells. Biochem Biophys Res Commun 238(1): 261-266

44. Gotoh N (2008) Regulation of growth factor signaling by FRS2 family docking/scaffold adaptor proteins. Canc Sci 99(7):1319-1325

45. Williams EJ, Walsh FS, Doherty P (1994) The production of arachidonic acid can account for calcium channel activation in the second messenger pathway underlying neurite outgrowth stimulated by NCAM, N-Cadherin, and L1. J Neurochem 62(3):12311234

46. Asimaki O, Leondaritis G, Lois G, Sakellaridis N, Mangoura D (2011) Cannabinoid 1 receptor-dependent transactivation of fibroblast growth factor receptor 1 emanates from lipid rafts and amplifies extracellular signal-regulated kinase $1 / 2$ activation in embryonic cortical neurons. J Neurochem 116(5):866-873

47. Dikic I, Giordano S (2003) Negative receptor signalling. Curr Opin Cell Biol 15(2):128-135

48. Mason JM, Morrison DJ, Basson MA, Licht JD (2006) Sprouty proteins: multifaceted negative-feedback regulators of receptor tyrosine kinase signaling. Trends Cell Biol 16(1):45-54

49. Hausott B, Klimaschewski L (2019) Sprouty2 - a novel therapeutic target in the nervous system? Mol Neurobiol 56:3897-3903

50. Zakrzewska M, Haugsten EM, Nadratowska-Wesolowska B, Oppelt A, Hausott B, Jin Y, Otlewski J, Wesche J, Wiedlocha A (2013) ERK-mediated phosphorylation of fibroblast growth factor receptor 1 on Ser777 inhibits signaling. Sci Signal 6 (262):ra11

51. Bache KG, Slagsvold T, Stenmark H (2004) Defective downregulation of receptor tyrosine kinases in cancer. EMBO J 23(14):2707-2712

52. Haglund K, Sigismund S, Polo S, Szymkiewicz I, Di Fiore PP, Dikic I (2003) Multiple monoubiquitination of RTKs is sufficient for their endocytosis and degradation. Nat Cell Biol 5(5):461-466

53. Wong A, Lamothe B, Lee A, Schlessinger J, Lax I, Li A (2002) FRS2 alpha attenuates FGF receptor signaling by Grb2-mediated recruitment of the ubiquitin ligase Cbl. Proc Natl Acad Sci USA 99(10):6684-6689

54. Csanaky K, Hess MW, Klimaschewski L (2019) Membrane-associated, not cytoplasmic or nuclear, FGFR1 induces neuronal differentiation. Cells 8(3):243

55. Hausott B, Rietzler A, Vallant N, Auer M, Haller I, Perkhofer S, Klimaschewski L (2011) Inhibition of fibroblast growth factor receptor 1 endocytosis promotes axonal branching of adult sensory neurons. Neuroscience 188:13-22

56. Irschick R, Trost T, Karp G, Hausott B, Auer M, Claus P, Klimaschewski L (2013) Sorting of the FGF receptor 1 in a human glioma cell line. Histochem Cell Biol 139(1):135-148

57. Hausott B, Schlick B, Vallant N, Dorn R, Klimaschewski L (2008) Promotion of neurite outgrowth by fibroblast growth factor receptor 1 overexpression and lysosomal inhibition of receptor degradation in pheochromocytoma cells and adult sensory neurons. Neuroscience 153(2):461-473

58. Hausott B, Vallant N, Hochfilzer M, Mangger S, Irschick R, Haugsten EM, Klimaschewski L (2012) Leupeptin enhances cell surface localization of fibroblast growth factor receptor 1 in adult sensory neurons by increased recycling. Eur $\mathrm{J}$ Cell Biol 91(2):129-138

59. Haugsten EM, Malecki J, Bjorklund SM, Olsnes S, Wesche J (2008) Ubiquitination of fibroblast growth factor receptor 1 is required for its intracellular sorting but not for its endocytosis. Mol Biol Cell 19(8):3390-3403

60. Hausott B, Förste A, Zach F, Mangger S, Haugsten EM, Klimaschewski L (2019) Endocytosis and transport of growth factor receptors in peripheral axon regeneration: novel lessons from neurons expressing lysine-deficient FGF receptor type 1 in vitro. Anat Rec 302:1268-1275
61. Francavilla C, Loeffler S, Piccini D, Kren A, Christofori G, Cavallaro U (2007) Neural cell adhesion molecule regulates the cellular response to fibroblast growth factor. J Cell Sci 120(24): 4388-4394

62. Hausott B, Klimaschewski L (2019) Promotion of peripheral nerve regeneration by stimulation of the extracellular signalregulated kinase (ERK) pathway. Anat Rec 302:1261-1267

63. Maddaluno L, Urwyler C, Werner S (2017) Fibroblast growth factors: key players in regeneration and tissue repair. Development 144(22):4047-4060

64. Wan J, Zhao XF, Vojtek A, Goldman D (2014) Retinal injury, growth factors, and cytokines converge on $\beta$-catenin and pStat3 signaling to stimulate retina regeneration. Cell Rep 9(1):285-297

65. Zhao M, Li D, Shimazu K, Zhou YX, Lu B, Deng CX (2007) Fibroblast growth factor receptor-1 is required for long-term potentiation, memory consolidation, and neurogenesis. Biol Psych 62(5):381-390

66. Eckenstein FP, McGovern T, Kern D, Deignan J (2006) Neuronal vulnerability in transgenic mice expressing an inducible dominant-negative FGF receptor. Exp Neurol 198(2):338-349

67. Zhang HY, Wang ZG, Wu FZ, Kong XX, Yang J, Lin BB, Zhu SP, Lin L et al (2013) Regulation of autophagy and ubiquitinated protein accumulation by bFGF promotes functional recovery and neural protection in a rat model of spinal cord Injury. Mol Neurobiol 48(3):452-464

68. Umemori H, Linhoff MW, Ornitz DM, Sanes JR (2004) FGF22 and its close relatives are presynaptic organizing molecules in the mammalian brain. Cell 118(2):257-270

69. Jacobi A, Loy K, Schmalz AM, Hellsten M, Umemori H, Kerschensteiner M, Bareyre FM (2015) FGF22 signaling regulates synapse formation during post-injury remodeling of the spinal cord. EMBO J 34(9):1231-1243

70. Terauchi A, Johnson-Venkatesh EM, Toth AB, Javed D, Sutton MA, Umemori H (2010) Distinct FGFs promote differentiation of excitatory and inhibitory synapses. Nature 465(7299):783-787

71. Dabrowski A, Terauchi A, Strong C, Umemori H (2015) Distinct sets of FGF receptors sculpt excitatory and inhibitory synaptogenesis. Development 142(10):1818-1830

72. Lee CH, Javed D, Althaus AL, Parent JM, Umemori H (2012) Neurogenesis is enhanced and mossy fiber sprouting arises in FGF7-deficient mice during development. Mol Cell Neurosci 51:61-67

73. Zechel S, Werner S, Unsicker K, Halbach O VB u (2010) Expression and functions of fibroblast growth factor 2 (FGF-2) in hippocampal formation. Neuroscientist 16(4):357-373

74. Paradiso B, Zucchini S, Simonato M (2013) Implication of fibroblast growth factors in epileptogenesis-associated circuit rearrangements. Front Cell Neurosci:7

75. Thau N, Jungnickel J, Knippenberg S, Ratzka A, Dengler R, Petri S, Grothe C (2012) Prolonged survival and milder impairment of motor function in the SOD1 ALS mouse model devoid of fibroblast growth factor 2. Neurobiol Dis 47(2):248-257

76. Itoh N, Ohta H (2013) Roles of FGF20 in dopaminergic neurons and Parkinson's disease. Front Mol Neurosci 6:15

77. Grothe C, Timmer M (2007) The physiological and pharmacological role of basic fibroblast growth factor in the dopaminergic nigrostriatal system. Brain Res Rev 54(1):80-91

78. Nandy SB, Mohanty S, Singh M, Behari M, Airan B (2014) Fibroblast growth factor-2 alone as an efficient inducer for differentiation of human bone marrow mesenchymal stem cells into dopaminergic neurons. J Biomed Sci 21(1):83

79. Sleeman IJ, Boshoff EL, Duty S (2012) Fibroblast growth factor20 protects against dopamine neuron loss in vitro and provides functional protection in the 6-hydroxydopamine-lesioned rat model of Parkinson's disease. Neuropharmacology 63(7):1268-1277 
80. Otto D, Unsicker K (1990) Basic FGF reverses chemical and morphological deficits in the nigrostriatal system of MPTPtreated mice. J Neurosci 10(6):1912-1921

81. Pankratova S, Bjornsdottir H, Christensen C, Zhang L, Li S, Dmytriyeva O, Bock E, Berezin V (2014) Immunomodulator CD200 promotes neurotrophic activity by interacting with and activating the fibroblast growth factor receptor. Mol Neurobiol 53(1):584-594

82. Katsouri L, Ashraf A, Birch AM, Lee KKL, Mirzaei N, Sastre M (2015) Systemic administration of fibroblast growth factor-2 (FGF2) reduces BACE1 expression and amyloid pathology in APP23 mice. Neurobiol Aging 36(2):821-831

83. Cheng Y, Li Z, Kardami E, Loh YP (2016) Neuroprotective effects of LMW and HMW FGF2 against amyloid beta toxicity in primary cultured hippocampal neurons. Neurosci Lett 632:109113

84. Noda M, Takii K, Parajuli B, Kawanokuchi J, Sonobe Y, Takeuchi H, Mizuno T, Suzumura A (2014) FGF-2 released from degenerating neurons exerts microglial-induced neuroprotection via FGFR3-ERK signaling pathway. J Neuroinflam 11(1):76

85. Kang W, Balordi F, Su N, Chen L, Fishell G, Hebert JM (2014) Astrocyte activation is suppressed in both normal and injured brain by FGF signaling. Proc Natl Acad Sci 111(29):E2987E2995

86. Ohkubo Y, Uchida AO, Shin D, Partanen J, Vaccarino FM (2004) Fibroblast growth factor receptor 1 is required for the proliferation of hippocampal progenitor cells and for hippocampal growth in mouse. J Neurosci 24(27):6057-6069

87. Sorrells SF, Paredes MF, Cebrian-Silla A, Sandoval K, Qi D, Kelley KW, James D, Mayer S et al (2018) Human hippocampal neurogenesis drops sharply in children to undetectable levels in adults. Nature 555(7696):377-381

88. Moreno-Jiménez EP, Flor-García M, Terreros-Roncal J, Rábano A, Cafini F, Pallas-Bazarra N, Ávila J, Llorens-Martín M (2019) Adult hippocampal neurogenesis is abundant in neurologically healthy subjects and drops sharply in patients with Alzheimer's disease. Nat Med 25(4):554-560

89. Nakatomi H, Kuriu T, Okabe S, S-i Y, Hatano O, Kawahara N, Tamura A, Kirino T et al (2002) Regeneration of hippocampal pyramidal neurons after ischemic brain injury by recruitment of endogenous neural progenitors. Cell 110(4):429-441

90. Yoshimura S, Teramoto T, Whalen MJ, Irizarry MC, Takagi Y, Qiu J, Harada J, Waeber C et al (2003) FGF-2 regulates neurogenesis and degeneration in the dentate gyrus after traumatic brain injury in mice. J Clin Invest 112(8):1202-1210

91. Ohori Y, S-i Y, Nagao M, Sugimori M, Yamamoto N, Nakamura K, Nakafuku M (2006) Growth factor treatment and genetic manipulation stimulate neurogenesis and oligodendrogenesis by endogenous neural progenitors in the injured adult spinal cord. $\mathrm{J}$ Neurosci 26(46):11948-11960

92. Kang W, Hebert JM (2015) FGF signaling is necessary for neurogenesis in young mice and sufficient to reverse its decline in old mice. J Neurosci 35(28):10217-10223

93. Berk BA, Vogler S, Pannicke T, Kuhrt H, Garcia TB, Wiedemann P, Reichenbach A, Seeger J et al (2015) Brain-derived neurotrophic factor inhibits osmotic swelling of rat retinal glial (Müller) and bipolar cells by activation of basic fibroblast growth factor signaling. Neuroscience 295:175-186

94. Fagel DM, Ganat Y, Cheng E, Silbereis J, Ohkubo Y, Ment LR, Vaccarino FM (2009) FGFR1 is required for cortical regeneration and repair after perinatal hypoxia. J Neurosci 29(4):1202-1211

95. Tsai MJ, Tsai SK, Huang MC, Liou DY, Huang SL, Hsieh WH, Huang WC, Huang SS et al (2015) Acidic FGF promotes neurite outgrowth of cortical neurons and improves neuroprotective effect in a cerebral ischemic rat model. Neuroscience 305:238-247
96. Huang B, Krafft PR, Ma Q, Rolland WB, Caner B, Lekic T, Manaenko A, Le M et al (2012) Fibroblast growth factors preserve blood-brain barrier integrity through RhoA inhibition after intracerebral hemorrhage in mice. Neurobiol Dis 46(1):204-214

97. Lee YS, Hsiao I, Lin VW (2002) Peripheral nerve grafts and aFGF restore partial hindlimb function in adult paraplegic rats. $\mathrm{J}$ Neurotrauma 19(10):1203-1216

98. Huang WC, Kuo HS, Tsai MJ, Ma H, Chiu CW, Huang MC, Yang LH, Chang PT et al (2011) Adeno-associated virus-mediated human acidic fibroblast growth factor expression promotes functional recovery of spinal cord-contused rats. J Gene Med 13(5):283-289

99. Goldshmit Y, Sztal TE, Jusuf PR, Hall TE, Nguyen-Chi M, Currie PD (2012) FGF-dependent glial cell bridges facilitate spinal cord regeneration in Zebrafish. J Neurosci 32(22):7477-7492

100. Haenzi B, Moon LD (2017) The function of FGFR1 signalling in the spinal cord: therapeutic approaches using FGFR1 ligands after spinal cord injury. Neural Plast 2017:2740768

101. Goldshmit Y, Frisca F, Pinto AR, Pebay A, Tang JK, Siegel AL, Kaslin J, Currie PD (2014) FGF2 improves functional recovery decreasing gliosis and increasing radial glia and neural progenitor cells after spinal cord injury. Brain Behav 4(2):187-200

102. Goldshmit Y, Frisca F, Kaslin J, Pinto AR, Tang JKKY, Pebay A, Pinkas-Kramarski R, Currie PD (2015) Decreased antiregenerative effects after spinal cord injury in spry4-/- mice. Neuroscience 287:104-112

103. Lee MJ, Chen CJ, Huang WC, Huang MC, Chang WC, Kuo HS, Tsai MJ, Lin YL et al (2011) Regulation of chondroitin sulphate proteoglycan and reactive gliosis after spinal cord transection: effects of peripheral nerve graft and fibroblast growth factor 1 . Neuropath Appl Neurobiol 37(6):585-599

104. Kang K, Lee SW, Han JE, Choi JW, Song MR (2014) The complex morphology of reactive astrocytes controlled by fibroblast growth factor signaling. Glia 62(8):1328-1344

105. Higginson JR, Thompson SM, Santos-Silva A, Guimond SE, Turnbull JE, Barnett SC (2012) Differential sulfation remodelling of heparan sulfate by extracellular 6-O-sulfatases regulates fibroblast growth factor-induced boundary formation by glial cells: Implications for glial cell transplantation. J Neurosci 32(45): 15902-15912

106. Teng YD, Mocchetti I, Taveira-DaSilva AM, Gillis RA, Wrathall JR (1999) Basic fibroblast growth factor increases long-term survival of spinal motor neurons and improves respiratory function after experimental spinal cord injury. J Neurosci 19(16):7037-7047

107. Tsai MC, Shen LF, Kuo HS, Cheng H, Chak KF (2008) Involvement of acidic fibroblast growth factor in spinal cord injury repair processes revealed by a proteomics approach. Mol Cell Proteomics 7(9):1668-1687

108. Huang MC, Lo MJ, Lin YL, Chang SE, Huang WC, Kuo WC, Tsai MJ, Kuo HS et al (2009) Functional recovery after the repair of transected cervical roots in the chronic stage of injury. $\mathrm{J}$ Neurotrauma 26(10):1795-1804

109. Anderson MA, O'Shea TM, Burda JE, Ao Y, Barlatey SL, Bernstein AM, Kim JH, James ND et al (2018) Required growth facilitators propel axon regeneration across complete spinal cord injury. Nature 561(7723):396-400

110. Ong SH, Guy GR, Hadari YR, Laks S, Gotoh N, Schlessinger J, Lax I (2000) FRS2 proteins recruit intracellular signaling pathways by binding to diverse targets on fibroblast growth factor and nerve growth factor receptors. Mol Cell Biol 20(3):979-989

111. Williams EJ, Mittal B, Walsh FS, Doherty P (1995) FGF inhibits neurite outgrowth over monolayers of astrocytes and fibroblasts expressing transfected cell adhesion molecules. J Cell Sci 108(11): $3523-3530$ 
112. Lee H, Raiker SJ, Venkatesh K, Geary R, Robak LA, Zhang Y, Yeh HH, Shrager P et al (2008) Synaptic function for the Nogo-66 receptor NgR1: regulation of dendritic spine morphology and activity-dependent synaptic strength. J Neurosci 28(11):2753-2765

113. Schwab ME (2010) Functions of Nogo proteins and their receptors in the nervous system. Nat Rev Neurosci 11(12):799-811

114. Auer M, Hausott B, Klimaschewski L (2011) Rho GTPases as regulators of morphological neuroplasticity. Ann Anat. 193(4): 259-266

115. Grothe C, Haastert K, Jungnickel J (2006) Physiological function and putative therapeutic impact of the FGF-2 system in peripheral nerve regeneration - lessons from in vivo studies in mice and rats. Brain Res Rev 51(2):293-299

116. Bryan DJ, Litchfield CR, Manchio JV, Logvinenko T, Holway AH, Austin J, Summerhayes IC, Rieger-Christ KM (2012) Spatiotemporal expression profiling of proteins in rat sciatic nerve regeneration using reverse phase protein arrays. Proteome Sci 10(1):9

117. Otto D, Unsicker K, Grothe C (1987) Pharmacological effects of nerve growth factor and fibroblast growth factor applied to the transectioned sciatic nerve on neuron death in adult rat dorsal root ganglia. Neurosci Lett 83(1-2):156-160

118. Aebischer P, Salessiotis AN, Winn SR (1989) Basic fibroblast growth factor released from synthetic guidance channels facilitates peripheral nerve regeneration across long nerve gaps. J Neurosci Res 23(3):282-289

119. Danielsen N, Pettmann B, Vahlsing HL, Manthorpe M, Varon S (1988) Fibroblast growth factor effects on peripheral nerve regeneration in a silicone chamber model. J Neurosci Res 20(3):320-330

120. Allodi I, Casals-Diaz L, Santos-Nogueira E, Gonzalez-Perez F, Navarro X, Udina E (2013) FGF-2 low molecular weight selectively promotes neuritogenesis of motor neurons in vitro. Mol Neurobiol 47(2):770-781

121. Timmer M, Robben S, Muller-Ostermeyer F, Nikkhah G, Grothe C (2003) Axonal regeneration across long gaps in silicone chambers filled with Schwann cells overexpressing high molecular weight FGF-2. Cell Transplant 12(3):265-277

122. Haastert K, Lipokatic E, Fischer M, Timmer M, Grothe C (2006) Differentially promoted peripheral nerve regeneration by grafted Schwann cells over-expressing different FGF-2 isoforms. Neurobiol Dis 21(1):138-153

123. Allodi I, Mecollari V, Gonzalez-Perez F, Eggers R, Hoyng S, Verhaagen J, Navarro X, Udina E (2014) Schwann cells transduced with a lentiviral vector encoding FGF-2 promote motor neuron regeneration following sciatic nerve injury. Glia 62(10): 1736-1746

124. Klimaschewski L, Nindl W, Feurle J, Kavakebi P, Kostron H (2004) Basic fibroblast growth factor isoforms promote axonal elongation and branching of adult sensory neurons in vitro. Neuroscience 126(2):347-353

125. Hausott B, Klimaschewski L (2016) Membrane turnover and receptor trafficking in regenerating axons. Eur J Neurosci 43(3): 309-317

126. Jungnickel J, Gransalke K, Timmer M, Grothe C (2004) Fibroblast growth factor receptor 3 signaling regulates injuryrelated effects in the peripheral nervous system. Mol Cell Neurosci 25(1):21-29

127. Jungnickel J, Haase K, Konitzer J, Timmer M, Grothe C (2006) Faster nerve regeneration after sciatic nerve injury in mice over-expressing basic fibroblast growth factor. J Neurobiol 66(9):940-948

128. Iwata Y, Ozaki N, Hirata H, Sugiura Y, Horii E, Nakao E, Tatebe M, Yazaki N et al (2006) Fibroblast growth factor-2 enhances functional recovery of reinnervated muscle. Muscle Nerve 34(5): 623-630

129. Seitz M, Grosheva M, Skouras E, Angelova SK, Ankerne J, Jungnickel J, Grothe C, Klimaschewski L et al (2011) Poor functional recovery and muscle polyinnervation after facial nerve injury in fibroblast growth factor-2-/- mice can be improved by manual stimulation of denervated vibrissal muscles. Neuroscience 182:241-247

130. Jungnickel J, Haastert K, Grzybek M, Thau N, Lipokatic-Takacs E, Ratzka A, Nolle A, Claus P et al (2010) Mice lacking basic fibroblast growth factor showed faster sensory recovery. Exp Neurol 223(1):166-172

131. Hausott B, Vallant N, Auer M, Yang L, Dai F, Brand-Saberi B, Klimaschewski L (2009) Sprouty2 down-regulation promotes axon growth by adult sensory neurons. Mol Cell Neurosci 42(4): 328-340

132. Hausott B, Vallant N, Schlick B, Auer M, Nimmervoll B, Obermair GJ, Schwarzer C, Dai F et al (2012) Sprouty2 and -4 regulate axon outgrowth by hippocampal neurons. Hippocampus 22:434-441

133. Marvaldi L, Thongrong S, Kozlowska A, Irschick R, Pritz CO, Bäumer B, Ronchi G, Geuna S et al (2015) Enhanced axon outgrowth and improved long-distance axon regeneration in sprouty2 deficient mice. Dev Neurobiol 75(3):217-231

134. Saffell JL, Williams EJ, Mason IJ, Walsh FS, Doherty P (1997) Expression of a dominant negative FGF receptor inhibits axonal growth and FGF receptor phosphorylation stimulated by CAMs. Neuron 18(2):231-242

135. Lom B, Hopker V, McFarlane S, Bixby JL, Holt CE (1998) Fibroblast growth factor receptor signaling in Xenopus retinal axon extension. J Neurobiol 37(4):633-641

136. Niethammer P, Delling M, Sytnyk V, Dityatev A, Fukami K, Schachner M (2002) Cosignaling of NCAM via lipid rafts and the FGF receptor is required for neuritogenesis. J Cell Biol 157(3):521-532

137. Chevet E, Lemaitre G, Janjic N, Barritault D, Bikfalvi A, Katinka MD (1999) Fibroblast growth factor receptors participate in the control of mitogen-activated protein kinase activity during nerve growth factor-induced neuronal differentiation of PC12 cells. J Biol Chem 274(30):20901-20908

138. Pot C, Simonen M, Weinmann O, Schnell L, Christ F, Stoeckle S, Berger P, Rulicke T et al (2002) Nogo-A expressed in Schwann cells impairs axonal regeneration after peripheral nerve injury. J Cell Biol 159(1):29-35

139. Hunt D, Mason MR, Campbell G, Coffin R, Anderson PN (2002) Nogo receptor mRNA expression in intact and regenerating CNS neurons. Mol Cell Neurosci 20(4):537-552

140. Josephson A, Trifunovski A, Widmer HR, Widenfalk J, Olson L, Spenger C (2002) Nogo-receptor gene activity: cellular localization and developmental regulation of mRNA in mice and humans. J Comp Neurol 453(3):292-304

141. Auer M, Schweigreiter R, Hausott B, Thongrong S, Höltje M, Just I, Bandtlow C, Klimaschewski L (2012) Rho-independent stimulation of axon outgrowth and activation of the ERK and Akt signaling pathways by $\mathrm{C} 3$ transferase in sensory neurons. Front Cell Neurosci 6:43

142. Liu H, Wu QF, Li JY, Liu XJ, Li KC, Zhong YQ, Wu D, Wang $Q$ et al (2015) Fibroblast growth factor 7 is a nociceptive modulator secreted via large dense-core vesicles. J Mol Cell Biol 7(5):466-475

143. Furusho M, Dupree JL, Bryant M, Bansal R (2009) Disruption of fibroblast growth factor receptor signaling in nonmyelinating Schwann cells causes sensory axonal neuropathy and impairment of thermal pain sensitivity. J Neurosci 29(6):1608-1614

144. Baum P, Vogt MA, Gass P, Unsicker K, Halbach O VB u (2016) FGF-2 deficiency causes dysregulation of Arhgef6 and 
downstream targets in the cerebral cortex accompanied by altered neurite outgrowth and dendritic spine morphology. Int J Dev Neurosci 50:55-64

145. Yamanaka H, Obata K, Kobayashi K, Dai Y, Fukuoka T, Noguchi K (2007) Activation of fibroblast growth factor receptor by axotomy, through downstream p38 in dorsal root ganglion, contributes to neuropathic pain. Neuroscience 150(1):202-211

146. Bansal R, Pfeiffer SE (1997) Regulation of oligodendrocyte differentiation by fibroblast growth factors. Adv Exp Med Biol 429: 69-77

147. Murtie JC, Zhou Y-X, Le TQ, Vana AC, Armstrong RC (2005) PDGF and FGF2 pathways regulate distinct oligodendrocyte lineage responses in experimental demyelination with spontaneous remyelination. Neurobiol Dis 19(1):171-182

148. Furusho M, Dupree JL, Nave KA, Bansal R (2012) Fibroblast growth factor receptor signaling in oligodendrocytes regulates myelin sheath thickness. J Neurosci 32(19):6631-6641

149. Ishii A, Furusho M, Dupree JL, Bansal R (2014) Role of ERK1/2 MAPK signaling in the maintenance of myelin and axonal integrity in the adult CNS. J Neurosci 34(48):16031-16045

150. Oh LYS, Denninger A, Colvin JS, Vyas A, Tole S, Ornitz DM, Bansal R (2003) Fibroblast growth factor receptor 3 signaling regulates the onset of oligodendrocyte terminal differentiation. J Neurosci 23(3):883-894

151. Lindner M, Thümmler K, Arthur A, Brunner S, Elliott C, McElroy D, Mohan H, Williams A et al (2015) Fibroblast growth factor signalling in multiple sclerosis: inhibition of myelination and induction of pro-inflammatory environment by FGF9. Brain 38: 1875-1893

152. Mohan H, Friese A, Albrecht S, Krumbholz M, Elliott CL, Arthur A, Menon R, Farina C et al (2014) Transcript profiling of different types of multiple sclerosis lesions yields FGF1 as a promoter of remyelination. Acta Neuropath Comm 2(1):178

153. Sarchielli P, Di Filippo M, Ercolani MV, Chiasserini D, Mattioni A, Bonucci M, Tenaglia S, Eusebi P et al (2008) Fibroblast growth factor-2 levels are elevated in the cerebrospinal fluid of multiple sclerosis patients. Neurosci Lett 435(3):223-228

154. Butt AM, Dinsdale J (2005) Fibroblast growth factor 2 induces loss of adult oligodendrocytes and myelin in vivo. Exp Neurol 192(1):125-133

155. Bribián A, Barallobre MJ, Soussi-Yanicostas N, de Castro F (2006) Anosmin-1 modulates the FGF-2-dependent migration of oligodendrocyte precursors in the developing optic nerve. Mol Cell Neurosci 33(1):2-14

156. Clemente D, Ortega MC, Arenzana FJ, de Castro F (2011) FGF-2 and Anosmin-1 are selectively expressed in different types of multiple sclerosis lesions. J Neurosci 31(42):14899-14909

157. Bribián A, Medina-Rodríguez EM, Josa-Prado F, García-Álvarez I, Machín-Díaz I, Esteban PF, Murcia-Belmonte V, Vega-Zelaya L et al (2020) Functional heterogeneity of mouse and human brain OPCs: relevance for preclinical studies in multiple sclerosis. J Clin Med 9(6):1681

158. Nakamura S, Todo T, Motoi Y, Haga S, Aizawa T, Ueki A, Ikeda K (1999) Glial expression of fibroblast growth factor-9 in rat central nervous system. Glia 28(1):53-65

159. Cohen RI, Chandross KJ (2000) Fibroblast growth factor-9 modulates the expression of myelin related proteins and multiple fibroblast growth factor receptors in developing oligodendrocytes. J Neurosci Res 61(3):273-287

160. Kuroda M, Muramatsu R, Maedera N, Koyama Y, Hamaguchi M, Fujimura H, Yoshida M, Konishi M et al (2017) Peripherally derived FGF21 promotes remyelination in the central nervous system. J Clin Invest 127(9):3496-3509

161. Harirchian MH, Tekieh AH, Modabbernia A, Aghamollaii V, Tafakhori A, Ghaffarpour M, Sahraian MA, Naji M et al (2012)
Serum and CSF PDGF-AA and FGF-2 in relapsing-remitting multiple sclerosis: a case-control study. Eur J Neurol 19(2):241-247

162. Furusho M, Roulois AJ, Franklin RJM, Bansal R (2015) Fibroblast growth factor signaling in oligodendrocyte-lineage cells facilitates recovery of chronically demyelinated lesions but is redundant in acute lesions. Glia 63(10):1714-1728

163. Armstrong RC, Le TQ, Frost EE, Borke RC, Vana AC (2002) Absence of fibroblast growth factor 2 promotes oligodendroglial repopulation of demyelinated white matter. J Neurosci 22(19): 8574-8585

164. Armstrong RC, Le TQ, Flint NC, Vana AC, Zhou Y-X (2006) Endogenous cell repair of chronic demyelination. J Neuropath Exp Neurol 65(3):245-256

165. Zhou Y-X, Pannu R, Le TQ, Armstrong RC (2012) Fibroblast growth factor 1 (FGFR1) modulation regulates repair capacity of oligodendrocyte progenitor cells following chronic demyelination. Neurobiol Dis 45(1):196-205

166. Mierzwa AJ, Zhou YX, Hibbits N, Vana AC, Armstrong RC (2013) FGF2 and FGFR1 signaling regulate functional recovery following cuprizone demyelination. Neurosci Lett 548:280-285

167. Rajendran R, Giraldo-Velasquez M, Stadelmann C, Berghoff M (2018) Oligodendroglial fibroblast growth factor receptor 1 gene targeting protects mice from experimental autoimmune encephalomyelitis through ERK/AKT phosphorylation. Brain Pathol 28(2):212-224

168. Ruffini F, Furlan R, Poliani PL, Brambilla E, Marconi PC, Bergami A, Desina G, Glorioso JC et al (2001) Fibroblast growth factor-II gene therapy reverts the clinical course and the pathological signs of chronic experimental autoimmune encephalomyelitis in C57BL/6 mice. Gene Ther 8(16):1207-1213

169. Kiyota T, Ingraham KL, Jacobsen MT, Xiong H, Ikezu T (2011) FGF2 gene transfer restores hippocampal functions in mouse models of Alzheimer's disease and has therapeutic implications for neurocognitive disorders. Proc Natl Acad Sci USA 108(49): E1339-E1348

170. Rajendran R, Giraldo Velásquez M, Stadelmann C, Berghoff M (2017) Oligodendroglial fibroblast growth factor receptor 1 gene targeting protects mice from experimental autoimmune encephalomyelitis through ERK/AKT phosphorylation. Brain Pathol 28(2):212-224

171. Figueiredo C, Pais TF, Gomes JR, Chatterjee S (2008) Neuronmicroglia crosstalk up-regulates neuronal FGF-2 expression which mediates neuroprotection against excitotoxicity via JNK1/2. J Neurochem 107(1):73-85

172. Rottlaender A, Villwock H, Addicks K, Kuerten S (2011) Neuroprotective role of fibroblast growth factor-2 in experimental autoimmune encephalomyelitis. Immunology 133(3):370-378

173. Zhou W, Du X, Song F, Zheng H, Chen K, Zhang W, Yang J (2016) Prognostic roles for fibroblast growth factor receptor family members in malignant peripheral nerve sheath tumor. Oncotarget 17(16):22234-22244

174. Rand V, Huang J, Stockwell T, Ferriera S, Buzko O, Levy S, Busam D, Li K et al (2005) Sequence survey of receptor tyrosine kinases reveals mutations in glioblastomas. Proc Natl Acad Sci U S A 102(40):14344-14349

175. Ohashi R, Matsuda Y, Ishiwata T, Naito Z (2014) Downregulation of fibroblast growth factor receptor 2 and its isoforms correlates with a high proliferation rate and poor prognosis in high-grade glioma. Oncol Rep 32(3):1163-1169

176. Cloughesy TF, Cavenee WK, Mischel PS (2013) Glioblastoma: from molecular pathology to targeted treatment. Ann Rev Pathol 9:1-25

177. Holland EC, Celestino J, Dai C, Schaefer L, Sawaya RE, Fuller GN (2000) Combined activation of Ras and Akt in neural progenitors induces glioblastoma formation in mice. Nat Genet 25(1):5557 
178. Park JW, Wollmann G, Urbiola C, Fogli B, Florio T, Geley S, Klimaschewski L (2018) Sprouty2 enhances the tumorigenic potential of glioblastoma cells. Neuro Oncol. 20(8):1044-1054

179. Maxwell M, Naber SP, Wolfe HJ, Hedley-Whyte ET, Galanopoulos T, Neville-Golden J, Antoniades HN (1991) Expression of angiogenic growth factor genes in primary human astrocytomas may contribute to their growth and progression. Cancer Res 51(4):1345-1351

180. Yamaguchi F, Saya H, Bruner JM, Morrison RS (1994) Differential expression of two fibroblast growth factor-receptor genes is associated with malignant progression in human astrocytomas. Proc Natl Acad Sci USA 91(2):484-488

181. Loilome W, Joshi AD, Rhys CM, Piccirillo S, Vescovi AL, Gallia GL, Riggins GJ (2009) Glioblastoma cell growth is suppressed by disruption of fibroblast growth factor pathway signaling. $\mathrm{J}$ Neurooncol 94(3):359-366

182. Morrison RS, Yamaguchi F, Saya H, Bruner JM, Yahanda AM, Donehower LA, Berger M (1994) Basic fibroblast growth factor and fibroblast growth factor receptor I are implicated in the growth of human astrocytomas. J Neurooncol 18(3):207-216

183. Cuevas P, Carceller F, Angulo J, Gonzblez-Corrochano R, Cuevas-Bourdier A, Gimqnez-Gallego G (2011) Antiglioma effects of a new, low molecular mass, inhibitor of fibroblast growth factor. Neurosci Lett 491(1):1-7

184. Wang Q, Du J, Xu B, Xu L, Wang X, Liu J, Wang J (2016) Silence of bFGF enhances chemosensitivity of glioma cells to temozolomide through the MAPK signal pathway. Acta Biochim Biophys Sin 48(6):501-508

185. Auguste P, Gürsel DB, Lemiere S, Reimers D, Cuevas P, Carceller F, Di Santo JP, Bikfalvi A (2001) Inhibition of fibroblast growth factor/fibroblast growth factor receptor activity in glioma cells impedes tumor growth by both angiogenesis-dependent and independent mechanisms. Cancer Res 61(4):1717-1726

186. Kargiotis O, Rao JS, Kyritsis AP (2006) Mechanisms of angiogenesis in gliomas. J Neurooncol 78(3):281-293

187. Toyoda K, Tanaka K, Nakagawa S, Thuy D, Ujifuku K, Kamada K, Hayashi K, Matsuo T et al (2013) Initial contact of glioblastoma cells with existing normal brain endothelial cells strengthen the barrier function via fibroblast growth factor 2 secretion: a new in vitro blood-brain barrier model. Cell Mol Neurobiol 33(4): 489-501

188. Gouaze-Andersson V, Delmas C, Taurand M, Martinez-Gala J, Evrard S, Mazoyer S, Toulas C, Cohen-Jonathan Moyal E (2016) FGFR1 induces glioblastoma radioresistance through the PLC $\gamma / \mathrm{Hifl} \alpha$ pathway. Cancer Res 76(10):3036-3044

189. Graham BM, Richardson R (2011) Memory of fearful events: the role of fibroblast growth factor- 2 in fear acquisition and extinction. Neuroscience 189:156-169

190. Turner CA, Watson S, Akil H (2012) The fibroblast growth factor family: neuromodulation of affective behavior. Neuron 76(1): 160-174

191. Terwisscha van Scheltinga AF, Bakker SC, Kahn RS, Kas MJH (2013) Fibroblast growth factors in neurodevelopment and psychopathology. Neuroscientist 19(5):479-494

192. Graham BM, Richardson R (2015) FIbroblast growth factor 2 as a new approach to fighting fear. JAMA Psy 72(10):959-960

193. FFv H, Leiter I, Rumpel R, Langenhagen A, Wedekind D, Häger C, Bleich A, Palme R et al (2019) FGF-2 isoforms influence the development of dopaminergic neurons in the murine substantia nigra, but not anxiety-like behavior, stress susceptibility, or locomotor behavior. Behav Brain Res 374:112113

194. Flajolet M, Wang Z, Futter M, Shen W, Nuangchamnong N, Bendor J, Wallach I, Nairn AC et al (2008) FGF acts as a cotransmitter through adenosine $\mathrm{A} 2 \mathrm{~A}$ receptor to regulate synaptic plasticity. Nat Neurosci 11:1402
195. Chaudhury S, Aurbach EL, Sharma V, Blandino P, Turner CA, Watson SJ, Akil H (2014) FGF2 is a target and a trigger of epigenetic mechanisms associated with differences in emotionality: partnership with H3K9me3. Proc Natl Acad Sci 111(32):11834 11839

196. Kao CY, Hsu YC, Liu JW, Lee DC, Chung YF, Chiu IM (2013) The mood stabilizer valproate activates human FGF1 gene promoter through inhibiting HDAC and GSK-3 activities. J Neurochem 126(1):4-18

197. Shi Y, Li Z, Xu Q, Wang T, Li T, Shen J, Zhang F, Chen J et al (2011) Common variants on 8 p12 and 1q24.2 confer risk of schizophrenia. Nat Genet 43:1224

198. Hashimoto K, Shimizu E, Komatsu N, Nakazato M, Okamura N, Watanabe H, Kumakiri C, Shinoda N et al (2003) Increased levels of serum basic fibroblast growth factor in schizophrenia. Psych Res 120(3):211-218

199. Pieper AA, Wu X, Han TW, Estill SJ, Dang Q, Wu LC, ReeceFincanon S, Dudley CA et al (2005) The neuronal PAS domain protein 3 transcription factor controls FGF-mediated adult hippocampal neurogenesis in mice. Proc Natl Acad Sci USA 102(39): 14052-14057

200. Evans SJ, Choudary PV, Neal CR, Li JZ, Vawter MP, Tomita H, Lopez JF, Thompson RC et al (2004) Dysregulation of the fibroblast growth factor system in major depression. Proc Natl Acad Sci USA 101(43):15506-15511

201. Birey F, Kloc M, Chavali M, Hussein I, Wilson M, Christoffel Daniel J, Chen T, Frohman Michael A et al (2015) Genetic and stress-induced loss of NG2 glia triggers emergence of depressivelike behaviors through reduced secretion of FGF2. Neuron 88(5): 941-956

202. Elsayed M, Banasr M, Duric V, Fournier NM, Licznerski P, Duman RS (2012) Antidepressant effects of fibroblast growth factor-2 in behavioral and cellular models of depression. Biol Psych 72(4):258-265

203. Mallei A, Shi B, Mocchetti I (2002) Antidepressant treatments induce the expression of basic fibroblast growth factor in cortical and hippocampal neurons. Mol Pharmacol 61(5):1017-1024

204. Kajitani N, Hisaoka-Nakashima K, Morioka N, Okada-Tsuchioka M, Kaneko M, Kasai M, Shibasaki C, Nakata Y et al (2012) Antidepressant acts on astrocytes leading to an increase in the expression of neurotrophic/growth factors: differential regulation of FGF-2 by noradrenaline. PLOS ONE 7(12):e51197

205. Bachis A, Mallei A, Cruz MI, Wellstein A, Mocchetti I (2008) Chronic antidepressant treatments increase basic fibroblast growth factor and fibroblast growth factor-binding protein in neurons. Neuropharmacology 55(7):1114-1120

206. Tang MM, Lin WJ, Pan YQ, Li YC (2018) Fibroblast Growth Factor 2 modulates hippocampal microglia activation in a neuroinflammation induced model of depression. Front Cell Neurosci 12:255

207. Williams AJ, Yee P, Smith MC, Murphy GG, Umemori H (2016) Deletion of fibroblast growth factor 22 (FGF22) causes a depression-like phenotype in adult mice. Behav Brain Res 307: $11-17$

208. Hafenbreidel M, Twining RC, Todd CR, Mueller D (2015) Blocking infralimbic basic fibroblast growth factor (bFGF or FGF2) facilitates extinction of drug seeking after cocaine selfadministration. Neuropsychopharmacology 40(13):2907-2915

209. Fornstedt B, Pileblad E, Carlsson A (1990) In vivo autoxidation of dopamine in guinea pig striatum increases with age. J Neurochem 55(2):655-659

210. Flores C, Samaha AN, Stewart J (2000) Requirement of endogenous basic fibroblast growth factor for sensitization to amphetamine. J Neurosci 20(2):RC55-RC55

211. Mueller D, Chapman CA, Stewart J (2006) Amphetamine induces dendritic growth in ventral tegmental area dopaminergic neurons 
in vivo via basic fibroblast growth factor. Neuroscience 137(3): 727-735

212. Li R, Zou S, Wu Y, Li Y, Khor S, Mao Y, He H, Xu K et al (2017) Heparin-based coacervate of bFGF facilitates peripheral nerve regeneration by inhibiting endoplasmic reticulum stress following sciatic nerve injury. Oncotarget 8(29):48086-48097

213. Ryu W, Huang Z, Prinz FB, Goodman SB, Fasching R (2007) Biodegradable micro-osmotic pump for long-term and controlled release of basic fibroblast growth factor. J Control Release 124(12):98-105

214. Hansen RK, Christensen C, Korshunova I, Kriebel M, Burkarth N, Kiselyov VV, Olsen M, Ostergaard S et al (2007) Identification of NCAM-binding peptides promoting neurite outgrowth via a heterotrimeric G-protein-coupled pathway. J Neurochem 103(4): 1396-1407

215. Li S, Christensen C, Kiselyov VV, Kohler LB, Bock E, Berezin V (2008) Fibroblast growth factor-derived peptides: functional agonists of the fibroblast growth factor receptor. J Neurochem 104(3): 667-682

216. Thomas TP, Shukla R, Kotlyar A, Kukowska-Latallo J, Baker JR Jr (2010) Dendrimer-based tumor cell targeting of fibroblast growth factor-1. Bioorg Med Chem Lett 20(2):700-703
217. Chen B, He J, Yang H, Zhang Q, Zhang L, Zhang X, Xie E, Liu C et al (2015) Repair of spinal cord injury by implantation of bFGF-incorporated HEMA-MOETACL hydrogel in rats. Sci Rep 5:9017

218. Mendell JR, Al-Zaidy S, Shell R, Arnold WD, Rodino-Klapac LR, Prior TW, Lowes L, Alfano L et al (2017) Single-dose gene-replacement therapy for spinal muscular atrophy. New Engl J Med 377(18):1713-1722

219. Wong LF, Goodhead L, Prat C, Mitrophanous KA, Kingsman SM, Mazarakis ND (2006) Lentivirus-mediated gene transfer to the central nervous system: therapeutic and research applications. Hum Gene Ther 17(1):1-9

220. Bharali DJ, Klejbor I, Stachowiak EK, Dutta P, Roy I, Kaur N, Bergey EJ, Prasad PN et al (2005) Organically modified silica nanoparticles: a nonviral vector for in vivo gene delivery and expression in the brain. Proc Natl Acad Sci U S A 102(32): 11539-11544

Publisher's Note Springer Nature remains neutral with regard to jurisdictional claims in published maps and institutional affiliations. 